\title{
MARGINAL EXPENSE OIL WELL WIRELESS SURVEILLANCE (MEOWWS)
}

Final Report

July $1999-J u l y ~ 2000$

By

Donald G. Nelson
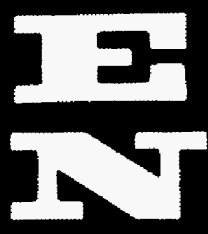

Date Published: March 2002
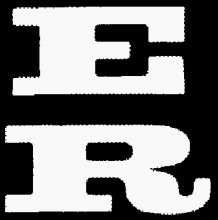

Work Performed Under Contract No. DE-FG26-99BC15246
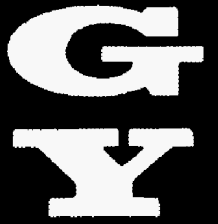

Hunter Edison Oil Development

Santa Barbara, California

\section{National Energy Technology Laboratory National Petroleum Technology Office U.S. DEPARTMENT OF ENERGY Tulsa, Oklahoma}




\section{DISCLAIMER}

This report was prepared as an account of work sponsored by an agency of the United States Government. Neither the United States Government nor any agency thereof, nor any of their employees, makes any warranty, expressed or implied, or assumes any legal liability or responsibility for the accuracy, completeness, or usefulness of any information, apparatus, product, or process disclosed, or represents that its use would not infringe privately owned rights. Reference herein to any specific commercial product, process, or service by trade name, trademark, manufacturer, or othenwise does not necessarily constitute or imply its endorsement, recommendation, or favoring by the United States Government or any agency thereof. The views and opinions of authors expressed herein do not necessarily state or reflect those of the United States Government.

This report has been reproduced directly from the best available copy. 


\title{
Marginal Expense Oil Well Wireless Surveillance (MEOWWS)
}

\author{
By \\ Donald G. Nelson
}

March 2002

Work Performed Under DE-FG26-99BC15246

\author{
Prepared for \\ U.S. Department of Energy \\ Assistant Secretary for Fossil Energy
}

Jim Barnes, Project Manager

National Petroleum Technology Office

P.O. Box 3628

Tulsa, OK 74101

Prepared by

Hunter Edison Oil Development

P.O. Box 5275

Santa Barbara, CA 93150 


\section{Table of Contents}

$\begin{array}{cl}\text { Page } & \text { Item } \\ \mathrm{v} & \text { Abstract } \\ 1 & \text { Introduction } \\ 3 & \text { Executive Summary } \\ 5 & \text { Experimental } \\ 5 & \text { Results and Discussion } \\ 5 & \text { Conclusion } \\ 5 & \text { References } \\ 5 & \text { Bibliography } \\ 5 & \text { Appendices }\end{array}$





\begin{abstract}
Wireless surveillance of rod pumped oil wells has typically involved mating high power radios with pump off controllers. These combinations are very effective but economic application is limited due to cost. A need exists for a simpler wireless surveillance system that can be economically applied to stripper wells. Continued breakthroughs in the technology sector have lead to lowered cost and improved quality for a variety of electronic components. This study involves a low cost, small, self-contained wireless vibration surveillance unit that can be bolted directly to the pumping unit. The device includes a shear-sensing transducer, battery, pre-programmed microchip, and low power radio transmitter. Signals related to the vibration behavior of the pumping unit are transmitted to a base station computer that will indicate an alarm condition when the well deviates from normal, pumped off performance.
\end{abstract}





\section{Introduction}

A portion of the Edison Oil Field of Kern County, California has the following well management challenges, common to many stripper operations:

- Infrequent production tests (1-4 per year) due to pooled flow lines and limited portable test separators and manpower

- Intermediate allocation meters do not flag problem wells due to low average rate per well (1-4 bopd/well)

- Most failed wells (no production) remain undetected until operator visually observes a smoking or black polish rod

- Worn pump systems producing at partial capacity (low production) remain undetected until a production test occurs

- Time clocks (proportional) on most wells complicate scheduling of manual surveillance such as visual observation of fluid pound

- The low average oil production rate per well will not provide benefits to justify existing, high cost, "off-the-shelf" systems

An opportunity exists for low cost, or marginal expense wireless surveillance to benefit the above-described system of oil wells through increased oil production and reduced electricity costs. Oil production would be increased due to earlier detection and repair of "no production" wells. Oil production would also be increased due to earlier detection and repair of "low production" wells. Electricity costs would be reduced as worn pumps are repaired and average pump efficiency increases.

Several alternatives to marginal expense oil well wireless surveillance were considered for the Edison stripper wells but were rejected due to cost as follows:

- Conventional wireless, pump-off control systems

- Individual flowlines and automatic well testing facilities

- Frequent manual dynamometer surveys

- Frequent manual fluid level surveys

- Frequent manual well tests with portable testers

Based on the above-described opportunity, an application for cost sharing was made to the United States Department of Energy (DOE) Technology Development with Independents program. The project was approved on July 21, 1999 as DOE Grant No. DE-FG26-99BC15246. This report details the results of the study. 


\section{Executive Summary}

The objective of this study was to identify and field test a new, low cost, wireless oil well surveillance system. A variety of suppliers and technologies were considered. One supplier and system was chosen that was low cost, new to the oil field, and successfully field tested.

The Internet was searched to develop a list of about 75 companies that appeared to have potential for supplying low-cost, state-of-the-art oil well wireless systems, software, sensors, radios, and/or base stations. In the end, a system and supplier identified at a local oil show was selected for the first phase of the study. In response to requests from their refinery customers, the supplier recently developed a low cost wireless vibration monitoring system to track performance trends of rotating machinery. The supplier proposed to apply the new system to monitor rod pumped oil well performance.

Industrial accelerometers consist of a piezoceramic material sandwiched beneath a seismic mass that creates a simple mass/spring system with a very high natural frequency. For reliable measurements, vibration sensors must be carefully selected to maximize signal-to-noise ratio for a specific application. Proper sensor installation is required to avoid problems such as mounting resonance, harmonic interference from AC line power, thermal transients causing uneven expansion of the sensor housing, shocks, truncated time waveform, bias shift, humidity, electrostatic discharge, mechanical noise, and corrosive chemicals and solvents.

The system chosen for this study used patented, self-contained units that each include a vibration sensor, radio transmitter, circuit board, and a 3.2-volt lithium battery in a weatherproof cylinder roughly 2 inches in diameter by 6 inches in length. The vibration sensor is a piezovelocity transducer employing a piezoceramic shear-sensing element and dense seismic mass to produce a charge output proportional to acceleration. For normal applications, the sample rate is set at one per minute, which provides a battery life of roughly one year.

The radio is low power $(<1 / 4$ Watt $)$ with a range of up to $3 / 4$ mile. No special license is required as it operates in the 900 -megahertz spread spectrum range. For locations beyond the $3 / 4$ mile range, repeaters may be employed. The base radio station interfaces with a $\mathrm{PC}$ where the vibration data is stored and processed. The lithium battery is serviceable.

Shallow, heavy oil wells in California are sometimes operated in a "pumped-off" condition for several reasons. When a well is pumped off, the fluid pound portion of the pump stroke mechanically transmits vibrations through the rod string, through the polish rod clamp, through the carrier bar, through the bridle, through the horse head, and into the pumping unit structure. The vibration behavior of a pumped off well will appear significantly different from that of a well with fluid over the pump. Monitoring pumping unit vibrations will allow deviation from the desirable pumped off condition to be identified early and timely corrective action scheduled to restore production, reduce power waste, and reduce the risk of further equipment damage. 
During initial testing, the sensor units were installed on a total of four wells. Two of the wells were pumped off and two of the wells had fluid over the pump. The sensors were tested in both the acceleration mode and the velocity mode. The sensors were positioned both vertically and horizontally on the polish rod and at the end of the walking beam near the horse head. The installation of the units took less than 5 minutes per well and merely involved placing a clamp on the polish rod or threading the support base onto a mounting stud welded or glued to the walking beam. Due to the self-contained nature of the sensors, no special wiring or skilled installation was required.

Sampling frequency was set at 4 samples per minute. This taxed the batteries but was necessary during the testing phase to obtain a statistically significant number of samples of the fluid pound portion of the pumping cycles.

Median values for acceleration were less than the mean for pumped off wells but similar for wells with fluid over the pump. Median velocity values were similar to the mean for both pumped off and non-pumped off wells. Based on the median/mean and standard deviation behavior, vibration acceleration measurements can be useful for confirming that a well is pumped off. Statistical analysis of the velocity measurements was not useful for determining whether a well is pumped off.

The results presented are preliminary and based on observation of only four wells. Further vibration monitoring work should be performed to improve the statistical basis of the conclusions by including more wells. Sensor design should be optimized in terms of:

- type: acceleration vs. velocity

- location: polish rod vs. beam

- orientation: vertical vs. horizontal

- frequency: 400 Hertz or lower?

- sample rate: minimize to extend battery life

Other improvements possible include installing off-the-shelf repeaters to extend range and development of a solar cell to eliminate the need to periodically service the battery. Another possible future development would involve placement of a low cost radio receiver in the pumping unit power box to convert the system from a simple surveillance system to a pump-off control system with a smart central computer.

In addition to vibration monitoring, further consideration should be given to linking other types of sensors with the low cost wireless system. Possibilities include non-invasive ultrasonic flow meters, temperature probes, and/or pressure transducers. 


\section{Experimental}

See Appendix 1.

\section{Results and Discussion}

See Appendix 1.

\section{Conclusion}

See Appendix 1.

\section{References}

See Appendix 1.

\section{Bibliography}

See Appendix 1.

\section{List of Acronyms and Abbreviations}

None.

\section{Appendices}

1. SPE 62865

2. Powerpoint Presentation \#1

3. Powerpoint Presentation \#2 



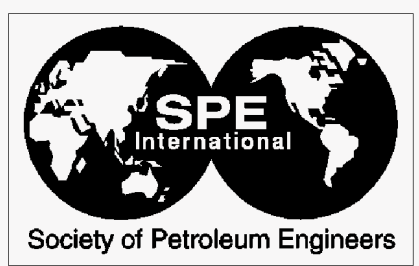

\section{SPE 62865}

\section{Marginal Expense Oil Well Wireless Monitoring}

Donald G. Nelson, SPE, Hunter Trust

Copyright 2000, Society of Petroleum Engineers Inc.

This paper was prepared for presentation at the 2000 SPE/AAPG Western Regional Meeting held in Long Beach, California, 19-23 June 2000.

This paper was selected for presentation by an SPE Program Committee following review of information contained in an abstract submitted by the author(s). Contents of the paper, as presented, have not been reviewed by the Society of Petroleum Engineers and are subject to correction by the author(s). The material, as presented, does not necessarily reflect any correction by the author(s). The material, as presented, does not necessarily reflect any
position of the Society of Petroleum Engineers, its officers, or members. Papers presented at SPE meetings are without the written consent of the Society of Petroleum Engineers is prohibited. Permission to reproduce in print is restricted to an abstract of not more than 300 words; illustrations may not be copied. The abstract must contain conspicuous acknowledgment of where and by whom the paper was presented. Write Librarian, SPE, P.O. Box 833836, Richardson, TX 75083-3836, U.S.A., fax 01-972-952-9435.

\section{Abstract}

Wireless surveillance of rod pumped oil wells has typically involved mating high power radios with pump off controllers. These combinations are very effective but economic application is limited due to cost. A need exists for a simpler wireless surveillance system that can be economically applied to stripper wells. Continued breakthroughs in the technology sector have lead to lowered cost and improved quality for a variety of electronic components. This study involves a low cost, small, self-contained wireless vibration surveillance unit that can be bolted directly to the pumping unit. The device includes a shear-sensing transducer, battery, pre-programmed microchip, and low power radio transmitter. Signals related to the vibration behavior of the pumping unit are transmitted to a base station computer that will indicate an alarm condition when the well deviates from normal, pumped off performance.

\section{Introduction}

A portion of the Edison Oil Field of Kern County, California has the following well management challenges, common to many stripper operations:

- Infrequent production tests (1-4 per year) due to pooled flow lines and limited portable test separators and manpower

- Intermediate allocation meters do not flag problem wells due to low average rate per well (1-4 bopd/well)

- Most failed wells (no production) remain undetected until operator visually observes a smoking or black polish rod

- Worn pump systems producing at partial capacity (low production) remain undetected until a production test occurs

- Time clocks (proportional) on most wells complicate scheduling of manual surveillance such as visual

\section{observation of fluid pound}

- The low average oil production rate per well will not provide benefits to justify existing, high cost, "off-theshelf' systems

An opportunity exists for low cost, or marginal expense wireless surveillance to benefit the above-described system of oil wells through increased oil production and reduced electricity costs. Oil production would be increased due to earlier detection and repair of "no production" wells. Oil production would also be increased due to earlier detection and repair of "low production" wells. Electricity costs would be reduced as worn pumps are repaired and average pump efficiency increases.

Several alternatives to marginal expense oil well wireless surveillance were considered for the Edison stripper wells but were rejected due to cost as follows:

- Conventional wireless, pump-off control systems

- Individual flowlines and automatic well testing facilities

- Frequent manual dynamometer surveys

- Frequent manual fluid level surveys

- Frequent manual well tests with portable testers

Based on the above-described opportunity, an application for cost sharing was made to the United States Department of Energy (DOE) Technology Development with Independents program. The project was approved on July 21, 1999 as DOE Grant No. DE-FG26-99BC15246. This paper summarizes the current status of the study.

\section{Search For New Surveillance Technologies}

The Internet was searched to develop a list of about 75 companies that appeared to have potential for supplying lowcost, state-of-the-art oil well wireless systems, software, sensors, radios, and/or base stations. A flyer was sent to each of these companies inviting proposals for participation in the study. In general it was found that most of the proposals that involved complete systems were very costly and therefor failed to meet the cost criteria for the study. Lower cost options involved piecing together unproven components with the additional complication of a "design" phase. Also, these options failed to meet the "of-the-shelf" criteria for the study.

In the end, a system and supplier identified at a local oil show was selected for the first phase of the study. The selected supplier had an eight-year track record in wireless emissions 
monitoring in refineries. The firm had developed and patented several powerful, yet low cost wireless solutions for data collection and control. In response to requests from their refinery customers, the supplier recently developed a low cost wireless vibration monitoring system to track performance trends of rotating machinery. The supplier proposed to apply the new system to monitor rod pumped oil well performance.

\section{Vibration Analysis}

Vibration is the periodic motion, i.e. shaking, of equipment. Measurement of machinery vibration can be likened to measurement of an EKG for a person. Vibration analysis first appeared within an academic curriculum in the 1930's based on a course of lectures presented in the Westinghouse Company Design School ${ }^{1}$ from 1926 to 1932 . The technology further progressed for military purposes beginning in the early 1950 's. Monitoring costs have been lowered and quality improved with recent advances in transducers and processing. Along with other predictive maintenance technologies, vibration analysis has been integrated into existing maintenance programs by a wide range of industries.

Vibrations of a discrete point on a rigid body take the form of a complex sine wave of displacement vs. time. The time domain total waveform is actually the sum of a variety of unique sine waves at various frequencies. In regular, cyclic vibration analysis, only one frequency at a time is of interest such as at a natural frequency, or resonant frequency. Viewed in the frequency domain, the total waveform can be shown as a spectral density plot of displacement vs. frequency. In random vibration analysis, vibration across a specific frequency range is averaged and evaluated.

Vibration measurements include displacement, velocity, and acceleration. Displacement is the distance a structure moves or vibrates from its at-rest position. Displacement units include 0 to peak, peak-to-peak, average, and root mean square. Velocity is the change in displacement with respect to time. Acceleration is the change in velocity with respect to time and is directly proportional to the force acting on an object.

Vibration Sensors. Westinghouse ${ }^{2}$ built some of the earliest vibration sensors in the 1930's using speaker voice coils. Driven by mechanical vibrations, the voice coil produces a voltage proportional to velocity. The voice coil evolved into the modern electrodynamic velocity sensor successfully used for many years. Today, most vibration measurements are made with accelerometers that internally convert the readings into velocity within the data collection instrumentation.

Industrial accelerometers consist of a piezoceramic material sandwiched beneath a seismic mass that creates a simple mass/spring system with a very high natural frequency. At frequencies below resonance, the mass applies a force to the piezoceramic proportional to the vibratory acceleration of the structure. In response to the applied force, the piezoceramic ${ }^{3}$ generates a proportional electric charge on its surface that is conditioned as necessary. For reliable measurements, vibration sensors must be carefully selected to maximize signal-to-noise ratio for a specific application. Proper sensor installation is required to avoid problems such as mounting resonance, harmonic interference from $\mathrm{AC}$ line power, thermal transients causing uneven expansion of the sensor housing, shocks, truncated time waveform, bias shift, humidity, electrostatic discharge, mechanical noise, and corrosive chemicals and solvents.

\section{Wireless Vibration Monitoring System}

The system chosen for this study (Fig. 1) uses patented, selfcontained units that each include a vibration sensor, radio transmitter, circuit board, and a 3.2-volt lithium battery in a weatherproof cylinder roughly 2 inches in diameter by 6 inches in length. The vibration sensor is a piezovelocity transducer employing a piezoceramic shear-sensing element and dense seismic mass to produce a charge output proportional to acceleration. Recent advances in miniaturization of hybrid circuits allow the sensor to simultaneously provide acceleration and velocity outputs. For purposes of initial testing, the transducers were pre-calibrated to measure vibration at a vibration frequency of $400 \mathrm{Hertz}$. Sampling frequency and mode (acceleration vs. velocity) is factory-set on the circuit board. Battery life is inversely proportional to sampling frequency. The system shuts off between samples and must power up before each new measurement is made. For normal applications, the sample rate is set at one per minute, which provides a battery life of roughly one year.

The radio is low power $(<1 / 4$ Watt) with a range of up to $3 / 4$ mile. No special license is required as it operates in the $900-$ megahertz spread spectrum range. For locations beyond the $3 / 4$ mile range, repeaters may be employed. The base radio station interfaces with a PC where the vibration data is stored and processed. The lithium battery is serviceable.

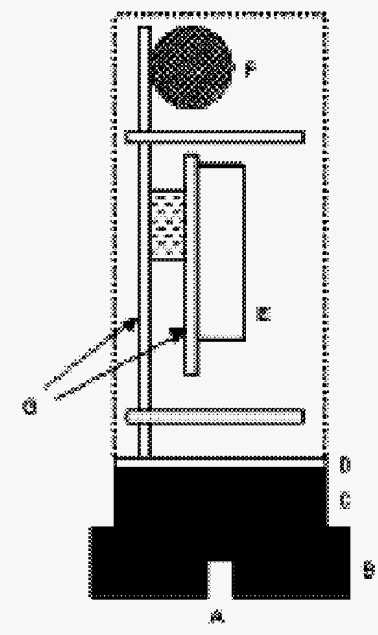

Figure 1: Schematic of the patented, self-contained vibration sensor/wireless transmitter unit (not to scale). A) 1/4" $\times 28$-thread mounting bore; B) stainless steel base; C) vibration sensing element and O-ring; D) sensor board; E) radio antenna; F) battery; G) circuit boards. 


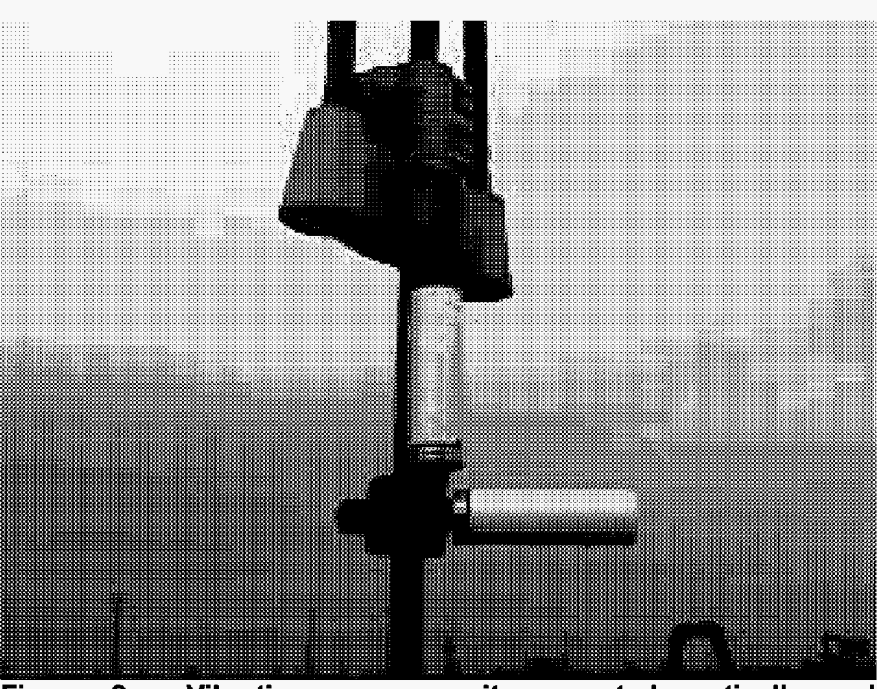

Figure 2: Vibration sensor units mounted vertically and horizontally on polish rod clamp.

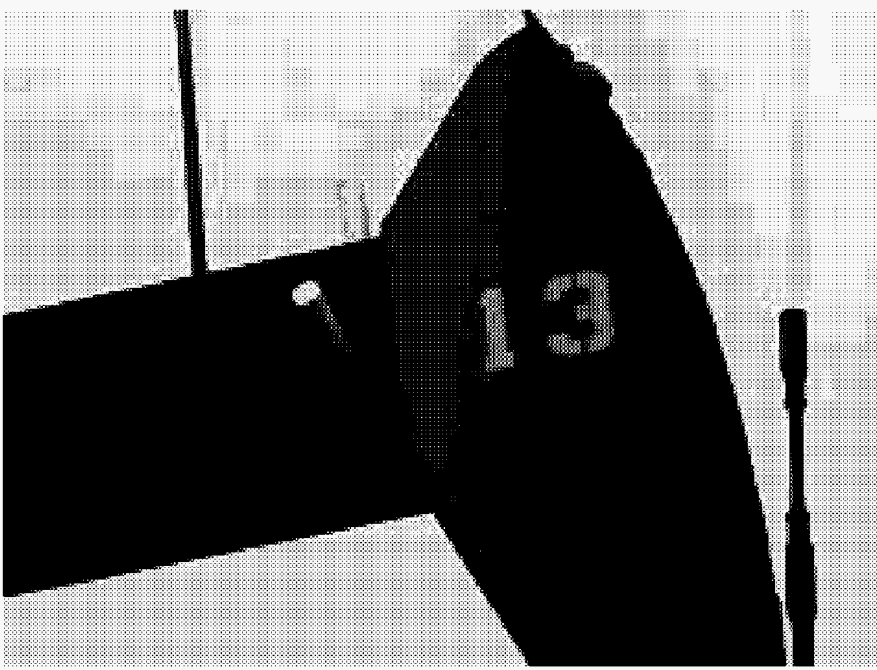

Figure 3: Vibration sensor units mounted vertically and horizontally on walking beam near horse head.

\section{Vibration of Shallow Well Pumping Units}

Shallow, heavy oil wells in California are sometimes operated in a pumped-off condition ${ }^{4,5}$ which offers several advantages:

- Operators are able to track the performance of their wells on a daily basis by visually observing the tell tale sign of fluid pound by the twist of the carrier bar on the down stroke

- Loss of fluid pound indicates a worn or failed pump system and triggers further troubleshooting and possible well servicing

- Drawdown is maximized and production is not limited by the artificial lift system

- Equipment wear and power losses are slight compared to the same effects in deeper wells and the benefits of early detection of pump problems

When a well is pumped off, the fluid pound portion of the pump stroke mechanically transmits vibrations through the rod string, through the polish rod clamp, through the carrier bar, through the bridle, through the horse head, and into the pumping unit structure. The vibration behavior of a pumped off well will appear significantly different from that of a well with fluid over the pump. Monitoring pumping unit vibrations will allow deviation from the desirable pumped off condition to be identified early and timely corrective action scheduled to restore production, reduce power waste, and reduce the risk of further equipment damage.

\section{Test Results}

During initial testing, the sensor units were installed on a total of four wells. Two of the wells were pumped off and two of the wells had fluid over the pump. The sensors were tested in both the acceleration mode and the velocity mode. The sensors were positioned both vertically and horizontally on the polish rod and at the end of the walking beam near the horse head as shown in Figures 2 and 3. The installation of the units took less than 5 minutes per well and merely involved placing a clamp on the polish rod or threading the support base onto a mounting stud welded or glued to the walking beam. Due to the self-contained nature of the sensors, no special wiring or skilled installation was required.

Sampling frequency was set at 4 samples per minute. This taxed the batteries but was necessary during the testing phase to obtain a statistically significant number of samples of the fluid pound portion of the pumping cycles. A summary of the results is shown in Table 1.

Table 1: Summary of the test results. Acceleration measurements showed greater variation for pumped off wells

\begin{tabular}{|c|c|c|c|c|c|c|c|c|c|}
\hline sensor type & location & orlentation & median & moan & $\begin{array}{l}\text { standard } \\
\text { deviation }\end{array}$ & \begin{tabular}{c|} 
standard \\
deviation \\
mean
\end{tabular} & $\begin{array}{c}\text { pumped } \\
\text { off? }\end{array}$ & $\begin{array}{c}\text { total } \\
\text { samples }\end{array}$ & well \\
\hline acceleration & polish rod & vertical & 0.24 & 0.64 & 0.74 & 1.16 & yes & 4359 & YF 46 \\
\hline acceleration & beam & horizontal & 0.07 & 0.1 & 0.11 & 1.10 & yes & 4313 & $\mathrm{H} 13$ \\
\hline acceleration & beam & vertical & 0.15 & 0.24 & 0.24 & 1.00 & yes & 3487 & $\mathrm{H} 13$ \\
\hline acceleration & polish rod & \begin{tabular}{|l|} 
horizontal \\
\end{tabular} & 007 & 0.08 & 0.0 & 0.8 & yes & 4132 & $\mathrm{H} 13$ \\
\hline acoeleration & polish rod & vertical & 0.12 & 0.14 & 0.09 & 0.64 & yes & 4157 & $\mathrm{H} 13$ \\
\hline acceleration & beam & vertical & 0.04 & 0.05 & 0.03 & 0.6 & no & 3734 & YF 69 \\
\hline acceleration & pollsh rod & vertical & 0.38 & 0.43 & 0.2 & 0.4 & no & 7262 & YF 11 \\
\hline acceleration & beam & \begin{tabular}{|l|} 
horizontal \\
\end{tabular} & 0.14 & 0.15 & 0.05 & 0.33 & no & 4299 & YF 69 \\
\hline veloc & beam & verti & 0.16 & 0.18 & & & & 3087 & YF 69 \\
\hline velocity & beam & vertical & 0.42 & 0.45 & 0.25 & 0.56 & yes & 1075 & $\mathrm{H} 13$ \\
\hline velocity & polish rod & vertical & 0.63 & 0.64 & 0.29 & & yes & 2054 & $\mathrm{H} 13$ \\
\hline velocity & beam & horizontal & 0.21 & 0.23 & 0.1 & 0.43 & yes & 4670 & H13 \\
\hline velocity & beam & & 0.6 & 0.08 & 00 & 03 & 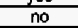 & 4413 & \\
\hline velocity & polish rod & \begin{tabular}{|l|} 
horizontal \\
\end{tabular} & 0.37 & 0.00 & 0. & & yes & 1351 & $\frac{H}{H} 13$ \\
\hline velocity & polish rod & horizontal & 0.37 & 0.37 & 0.09 & 0.24 & no & 4729 & YF 11 \\
\hline
\end{tabular}

whereas velocity measurement variation showed no relation to fluid pound.

Young Fee 46. This well was pumped off, was out of balance, and had a severe fluid pound as shown in Figure 4. The well is beam-balanced with a 48 -inch stroke length at 10.9 strokes per minute with a 2-inch pump at 1932 feet. This condition provided significant vibration as shown in Figure 5. The transmitter was about $1 / 2$ mile away from the base station . 


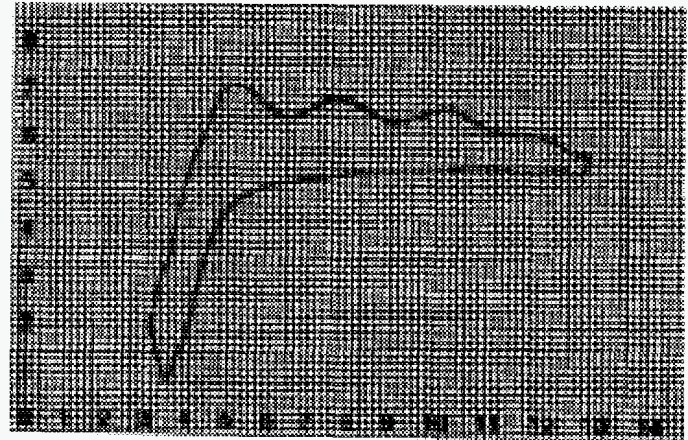

Figure 4: Young Fee 46 surface strain gauge dynamometer card. This confirmed the severe fluid pound and out of balance condition.

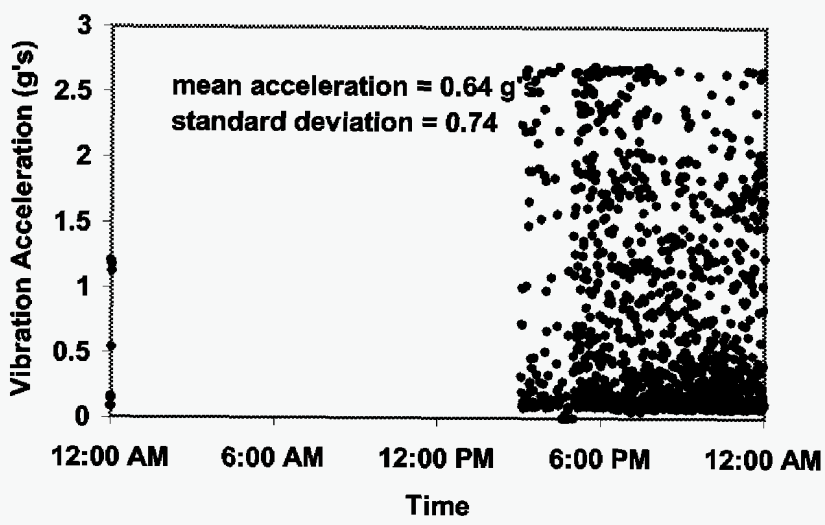

Figure 5: Young Fee 46 vibration acceleration observations. The sensor was mounted vertically on the polish rod.

Hershey 13. This well was on a time clock and pumped off within 5 minutes of the start of each pumping cycle. The pumping unit is an older conventional crank-balanced unit with a single pitman. The fluid pound occurs slower and with less intensity than the Young Fee 46 fluid pound as shown in Figure 6. The well has a 43 -inch stroke length at 11.7 strokes per minute with a 2-inch pump at 1754 feet. The transmitter was about 900 feet from the base station. Vibration data reflects the on/off nature of a time clock well as shown in Figure 7.

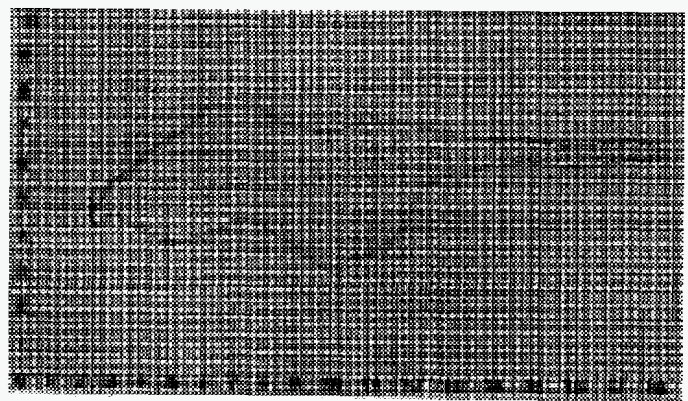

Figure 6: Hershey 13 surface strain gauge dynamometer card. The well showed fluid pound within 5 minutes of the start of each pumping cycle.

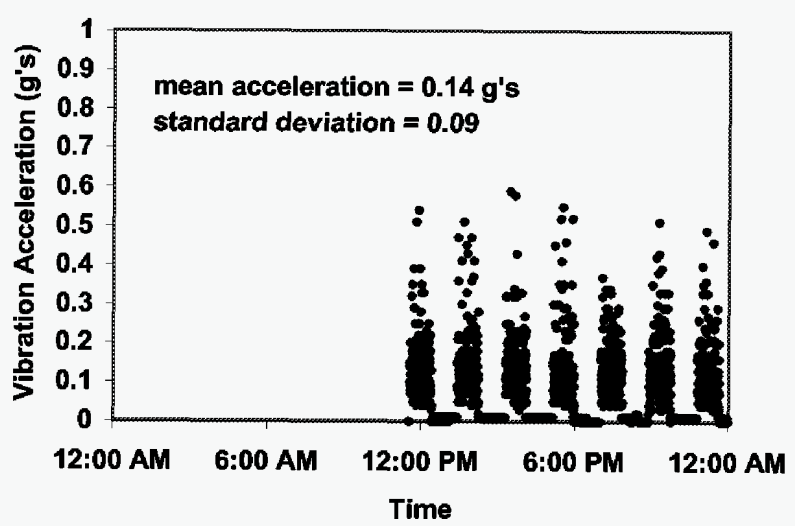

Figure 7: Hershey 13 vibration acceleration observations. The sensor was mounted vertically on the polish rod.

Young Fee 11. This well is air balanced, with a 100 -inch stroke length at 10.5 strokes per minute with a 2-inch pump at 2009 feet. As shown in Figure 8, this system has no fluid pound but has some over travel and rod string vibration. This well is operated without fluid pound due to severe water coning. The mean vibration is high as shown in Figure 9, due to the rod string vibrations. The transmitter was about $1 / 2$ mile away from the base station.

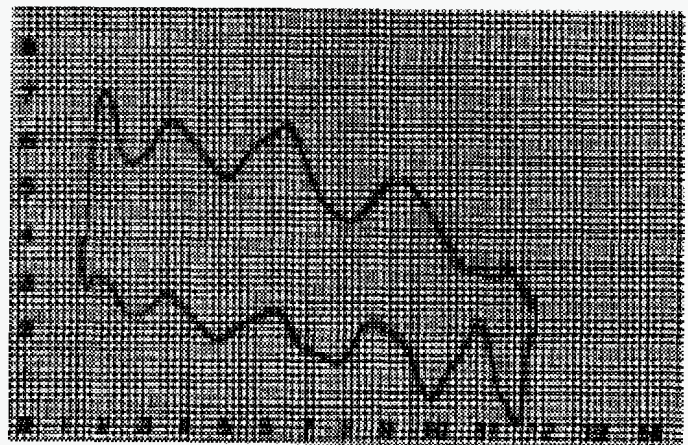

Figure 8: Young Fee 11 surface strain gauge dynamometer card. The card indicates no fluid pound with some over travel and rod string vibration.

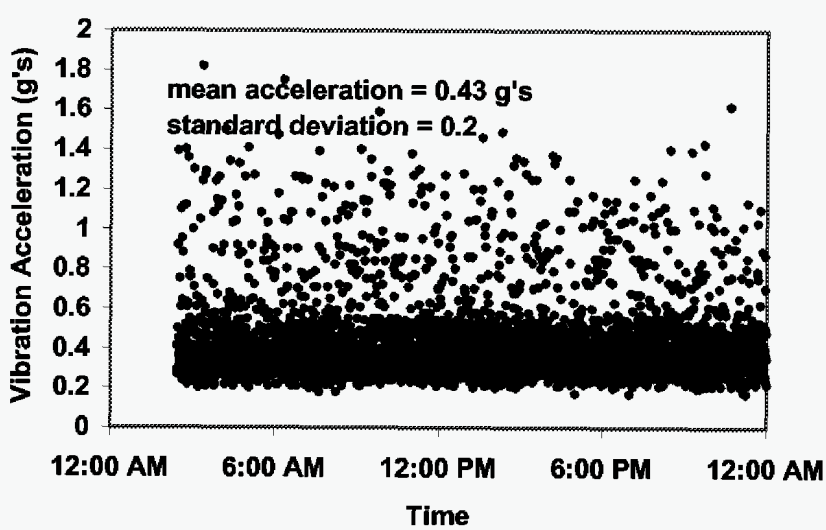

Figure 9: Young Fee 11 vibration acceleration observations. The sensor was mounted vertically on the polish rod. 
Young Fee 69. This well was on a time clock. The well has a 54-inch stroke length at 12 strokes per minute with a 2-inch pump at 1701 feet. The pumping unit is a conventional crankbalanced unit. The timer hours on this well are set high probably due to the inefficient pump with a worn plunger and/or traveling valve as indicated by the dynamometer card shown in Figure 10. The well normally produces in a pumped off mode but carries a high fluid level now due to the worn pump. As shown in Figure 11, lack of fluid pound in this well leads to low standard deviation in the vibration acceleration measurements. The transmitter was about 1100 feet from the base station.

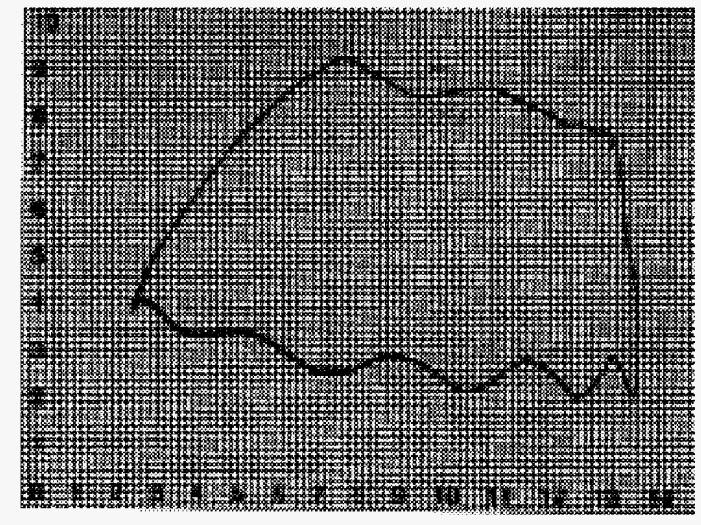

Figure 10: Young Fee 69 surface strain gauge dynamometer card. The card indicates a worn plunger and/or traveling valve with no fluid pound.

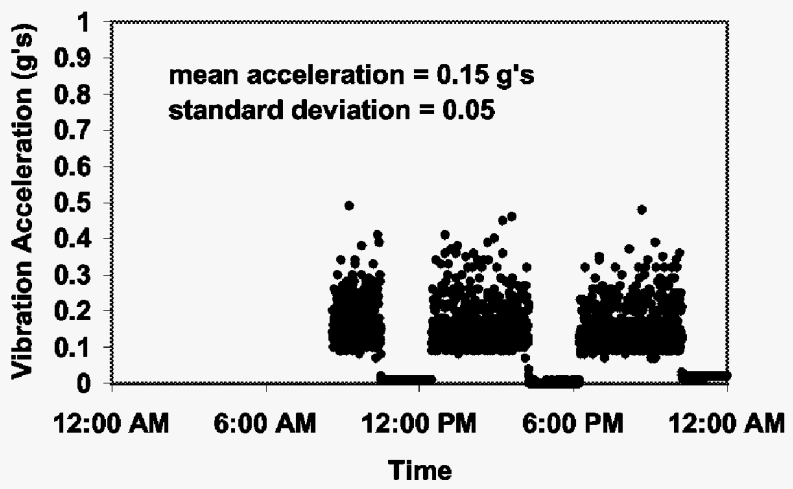

Figure 11: Young Fee 69 vibration acceleration observations. The sensor was mounted horizontally on the beam.

\section{Statistical Analysis}

As shown in Table 1, statistical analysis of the data was made including median, mean, and standard deviation. Median values for acceleration were less than the mean for pumped off wells but similar for wells with fluid over the pump. Median velocity values were similar to the mean for both pumped off and non-pumped off wells. Based on the median/mean and standard deviation behavior, vibration acceleration measurements can be useful for confirming that a well is pumped off. Statistical analysis of the velocity measurements was not useful for determining whether a well is pumped off. This is further shown in Figures 12 and 13.

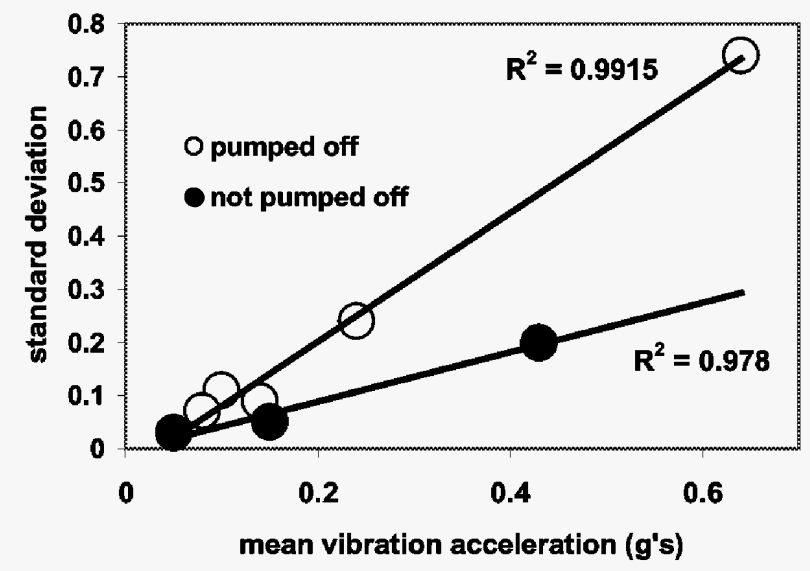

Figure 12: Plot of mean acceleration vs. standard deviation for all of the acceleration data summarized in Table 1 . For the data presented, standard deviation/mean of the pumped off wells is about double that off wells with fluid over the pump.

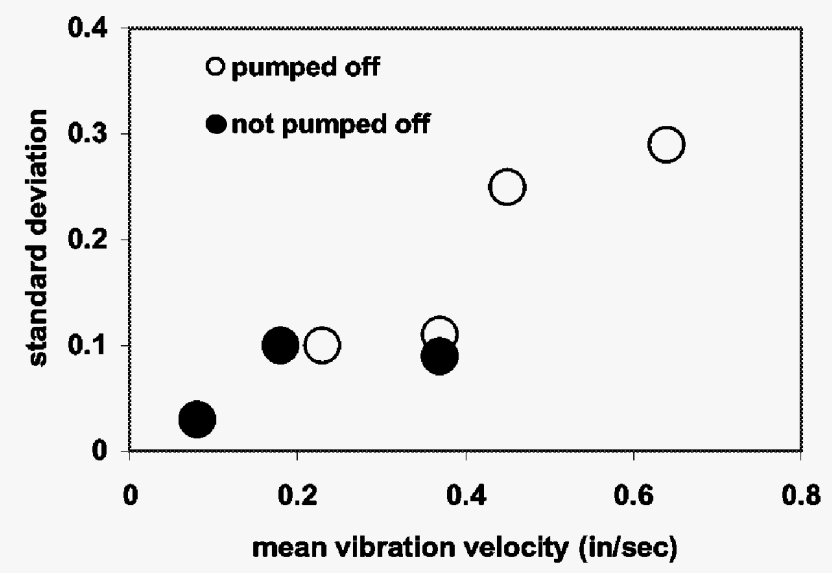

Figure 13: Plot of mean velocity vs. standard deviation for all of the velocity data summarized in Table 1 . For the data presented, there appears to be no way to differentiate between pumped off wells and wells with fluid over the pump based on vibration velocity surveillance.

\section{Additional Work}

The results presented are preliminary and based on observation of only four wells. Further vibration monitoring work is planned to improve the statistical basis of the conclusions by including more wells. Sensor design will be optimized in terms of:

- type: acceleration vs. velocity

- location: polish rod vs. beam

- orientation: vertical vs. horizontal

- frequency: $400 \mathrm{Hertz}$ or lower?

- sample rate: minimize to extend battery life

Other improvements planned include installing off-theshelf repeaters to extend range and development of a solar cell to eliminate the need to periodically service the battery. Another possible future development would involve 
placement of a low cost radio receiver in the pumping unit power box to convert the system from a simple surveillance system to a pump-off control system with a smart central computer.

In addition to vibration monitoring, further consideration will be given to linking other types of sensors with the low cost wireless system. Possibilities include non-invasive ultrasonic flow meters, temperature probes, and/or pressure transducers.

\section{Conclusions}

1. Despite the recent proliferation of the Internet as a marketing medium, trade shows are still effective for matching new products with economic opportunities.

2. Low power, spread-spectrum radio transmitters (without repeaters) can be effectively deployed for well surveillance in a flat, treeless oil field within a radius of over $1 / 2$ mile.

3. In some wells, acceleration sensors are useful for detecting mechanical vibrations associated with fluid pound. Pumped off wells show greater deviation in vibration acceleration than non-pumped off wells.

4. A new low cost system for wireless surveillance of oil wells has been successfully field-tested.

\section{Acknowledgments}

The author thanks Ken Hunter III, President of Hunter Trust for his interest and support in developing low cost wireless technology; Jim Barnes, United States Department of Energy Project Manager for his guidance and support; Mark Ralston and Lee Sherwood of Frontline Technologies for believing the FEDD wireless system would work in the oil patch; Rick Lawson, President of FEDD Systems for his direct involvement and confidence in our project; and Richard Cline of Integrated Information Technologies for modifying the FEDD System base station software as required for the project.

\section{References}

1. Den Hartog, J. P.: Mechanical Vibrations, reprint by Dover Publications, New York (1985) v.

2. Wilcoxon Research: "Industrial Vibration Sensor Selection: Piezovelocity Transducers (PVT)", Technical Note 18, Gaithersburg, Maryland (1993) 1.

3. Wilcoxon Research: "Industrial Vibration Sensor Selection: Piezovelocity Transducers (PVT)", Technical Note 18, Gaithersburg, Maryland (1993) 3.

4. Acton, J. F.: "Pump-Off Controller Application For Midway-Sunset Cyclic Steam Operations," paper SPE 9915 presented at the 1981 SPE California Regional Meeting, Bakersfield, California, March 25-26.

5. Randle, J. S.: "Low Cost Rod Pumping Management in Kern River Field," paper SPE 37501 presented at the 1997 SPE Production Operations Symposium, Oklahoma City, Oklahoma, March 9-11. 


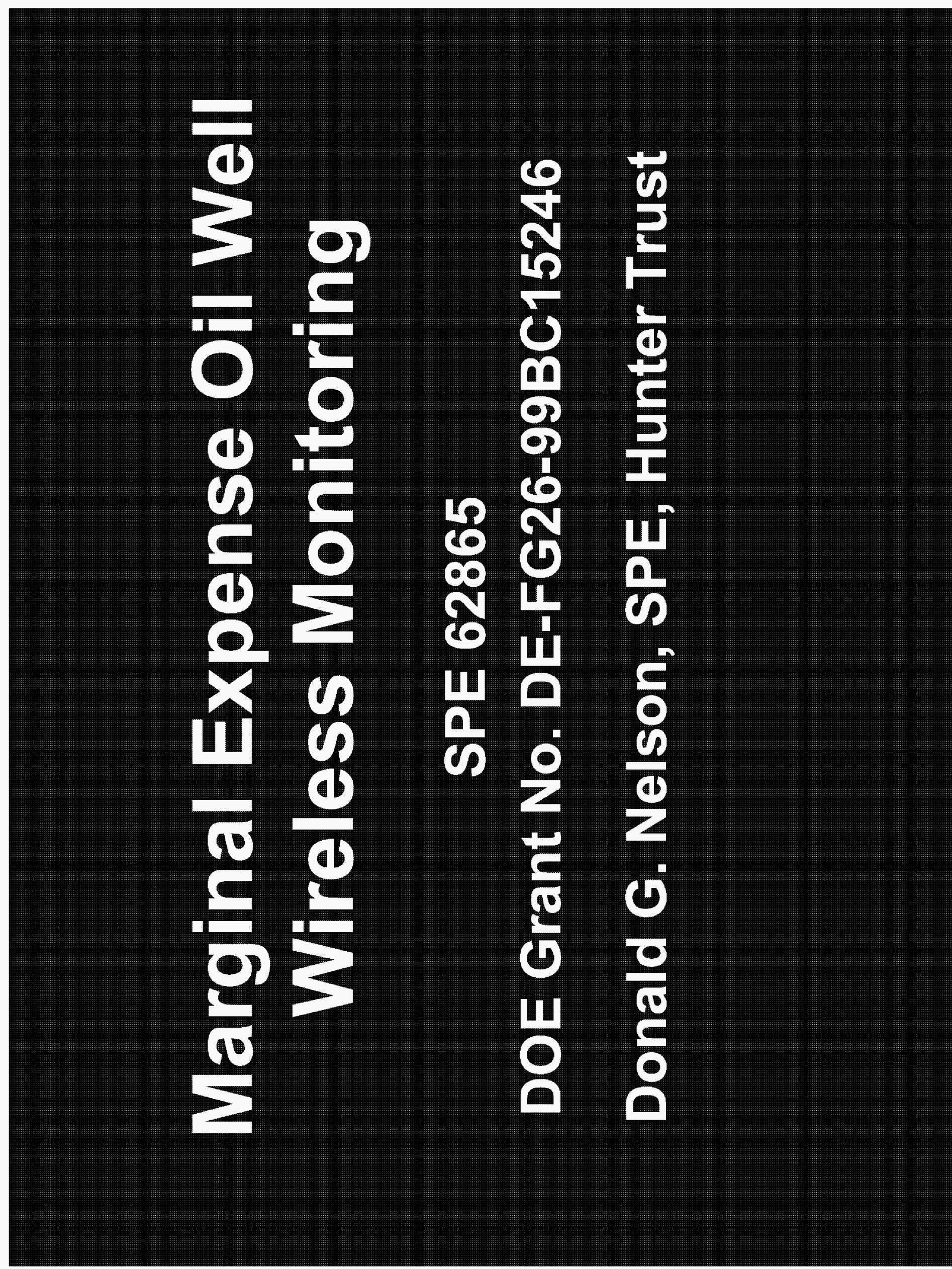




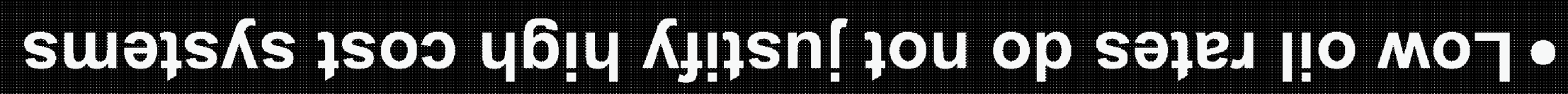

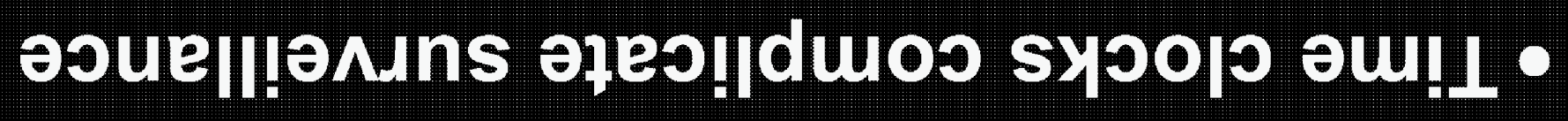

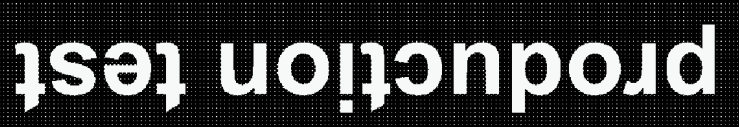

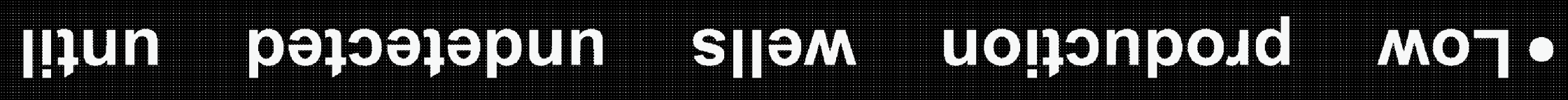
soyous

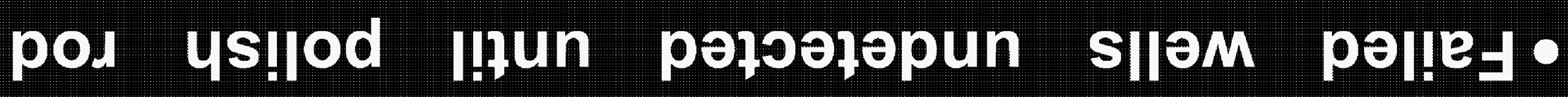

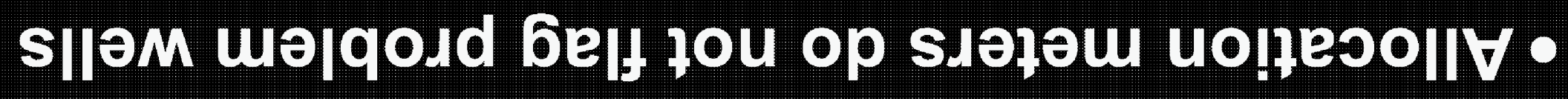
słsę uolfonpoid quenbajul • s\|ləM Jedd!ns doy

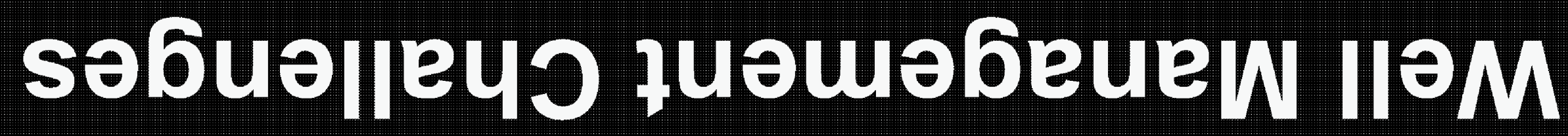




\section{Rejected, High-Cost Alternatives}

- Conventional wireless, pump-off control systems

- Individual flow lines and automatic well testing facilities

- Frequent dynamometer surveys

- Frequent fluid level surveys

- Frequent well tests with portable testers 

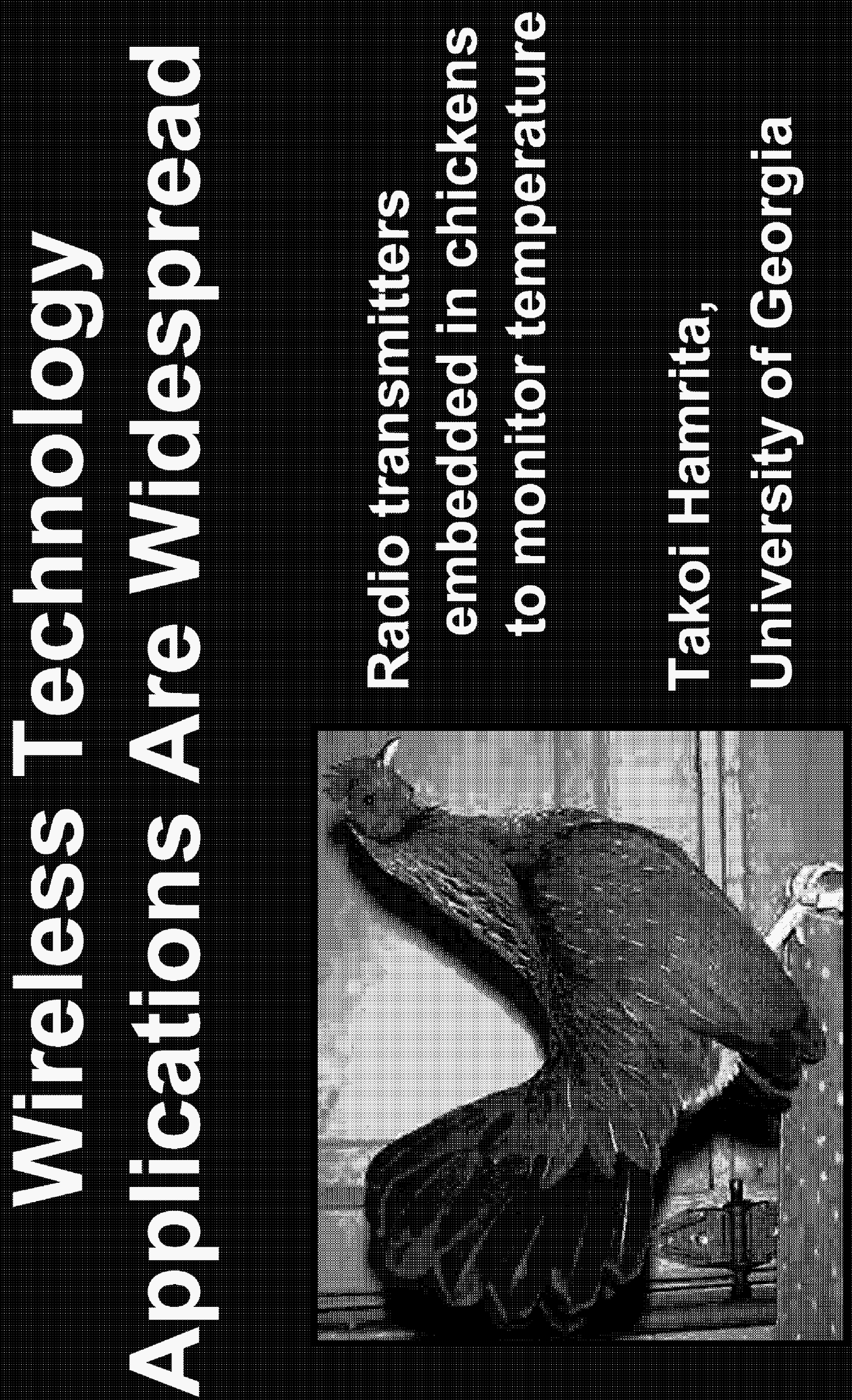


\section{Vibration Sensor/Wireless Transmitter Unit}

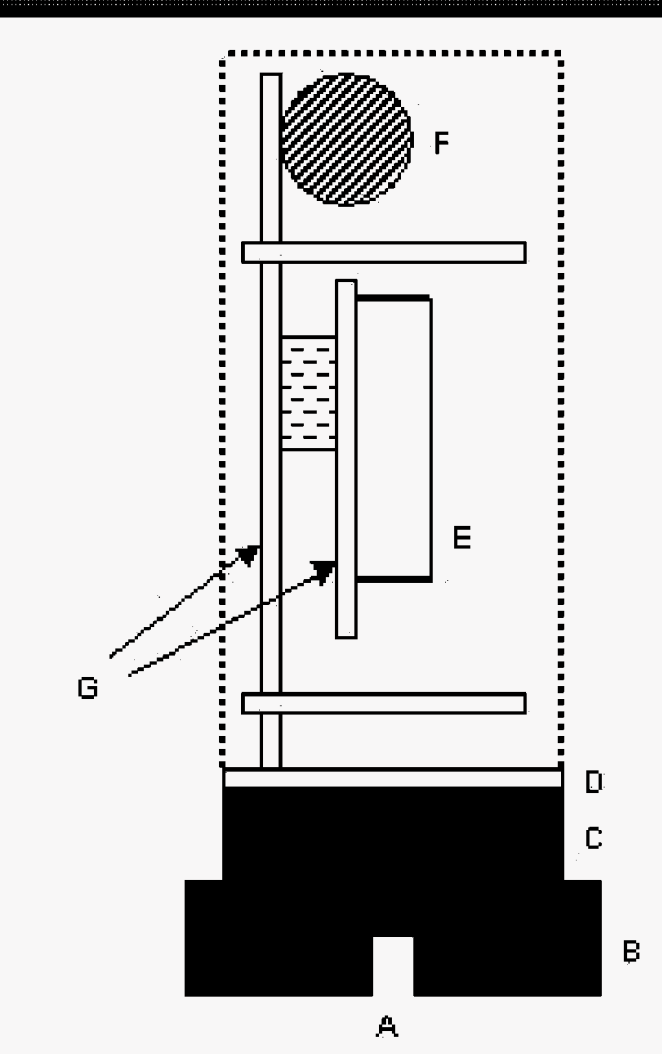

A) 1/4" $X$ 28-thread mounting bore

B) stainless steel base

C) vibration sensing element and O-ring

D) sensor board

E) radio antenna

F) battery

G) circuit boards. 


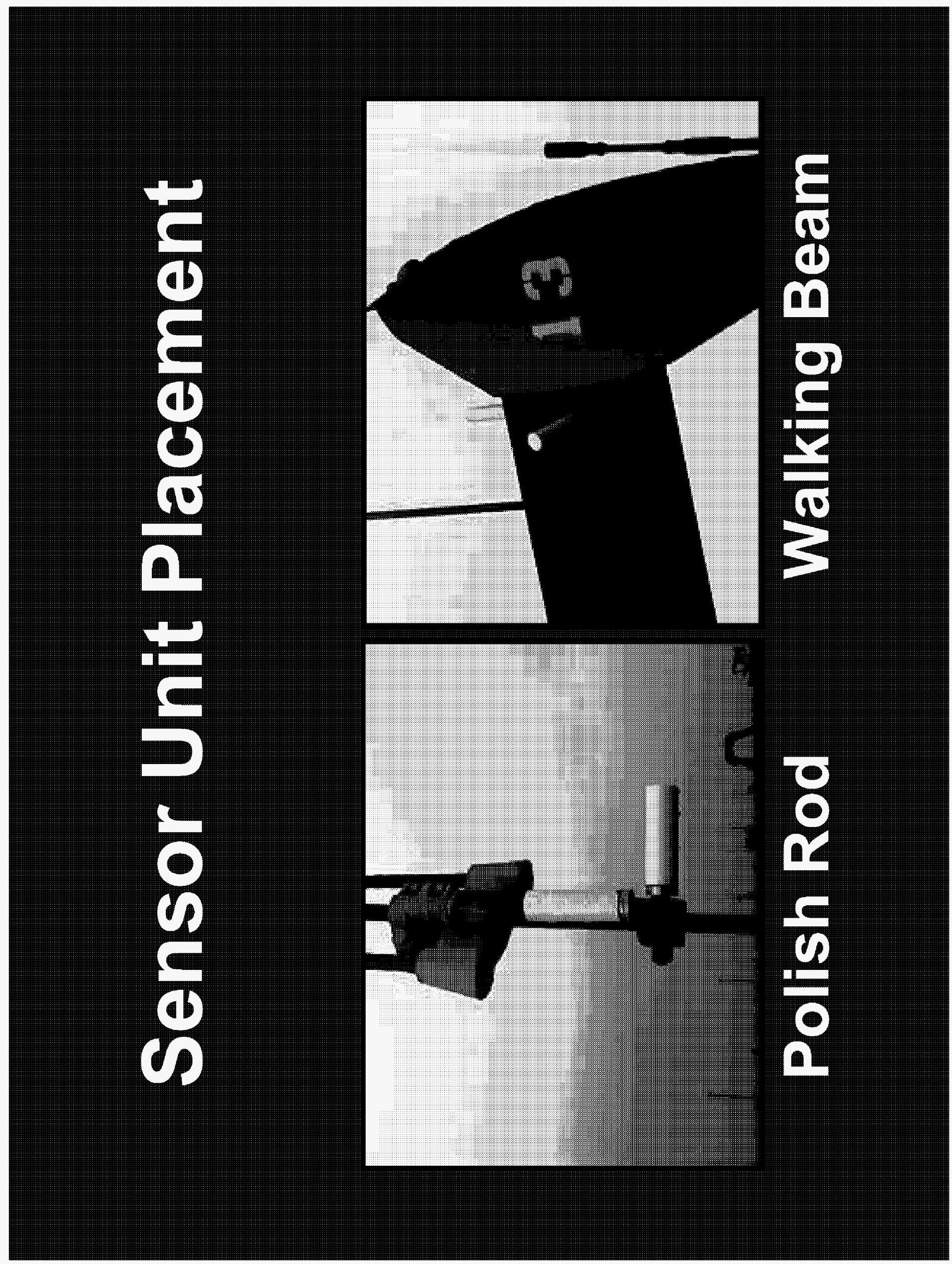




\section{Why Wells Are Pumped Off In California}

- Operators can track daily

- Loss of fluid pound triggers further troubleshooting

- Drawdown maximized

- Equipment wear and power losses slight in shallow wells 


\section{Test Results Summary}

\begin{tabular}{|c|c|c|c|c|c|c|c|c|c|c|} 
sensor type & location & orientation & median & mean & $\begin{array}{c}\text { standard } \\
\text { deviation }\end{array}$ & $\begin{array}{c}\text { standard } \\
\text { deviation/ } \\
\text { mean }\end{array}$ & $\begin{array}{c}\text { pumped } \\
\text { off? }\end{array}$ & $\begin{array}{c}\text { total } \\
\text { samples }\end{array}$ & well \\
\hline acceleration & polish rod & vertical & 0.24 & 0.64 & 0.74 & 1.16 & yes & 4359 & YF 46 \\
\hline acceleration & beam & horizontal & 0.07 & 0.1 & 0.11 & 1.10 & yes & 4313 & $\mathrm{H} 13$ \\
\hline acceleration & beam & vertical & 0.15 & 0.24 & 0.24 & 1.00 & yes & 3487 & $\mathrm{H} 13$ \\
\hline acceleration & polish rod & horizontal & 0.07 & 0.08 & 0.07 & 0.88 & yes & 4132 & $\mathrm{H} 13$ \\
\hline acceleration & polish rod & vertical & 0.12 & 0.14 & 0.09 & 0.64 & yes & 4157 & $\mathrm{H} 13$ \\
\hline acceleration & beam & vertical & 0.04 & 0.05 & 0.03 & 0.60 & no & 3734 & YF 69 \\
\hline acceleration & polish rod & vertical & 0.38 & 0.43 & 0.2 & 0.47 & no & 7262 & YF 11 \\
\hline acceleration & beam & horizontal & 0.14 & 0.15 & 0.05 & 0.33 & no & 4299 & YF 69 \\
\hline velocity & beam & vertical & 0.16 & 0.18 & 0.1 & 0.56 & no & 3087 & YF 69 \\
\hline velocity & beam & vertical & 0.42 & 0.45 & 0.25 & 0.56 & yes & 1075 & $\mathrm{H} 13$ \\
\hline velocity & polish rod & vertical & 0.63 & 0.64 & 0.29 & 0.45 & yes & 2054 & $\mathrm{H} 13$ \\
\hline velocity & beam & horizontal & 0.21 & 0.23 & 0.1 & 0.43 & yes & 4670 & $\mathrm{H} 13$ \\
\hline velocity & beam & horizontal & 0.08 & 0.08 & 0.03 & 0.38 & no & 4413 & YF 69 \\
\hline velocity & polish rod & horizontal & 0.37 & 0.37 & 0.11 & 0.30 & yes & 1351 & $\mathrm{H} 13$ \\
\hline velocity & polish rod & horizontal & 0.37 & 0.37 & 0.09 & 0.24 & no & 4729 & YF 11 \\
\hline
\end{tabular}




\section{Young Fee 46 \\ Pumped Off With Severe Fluid Pound}
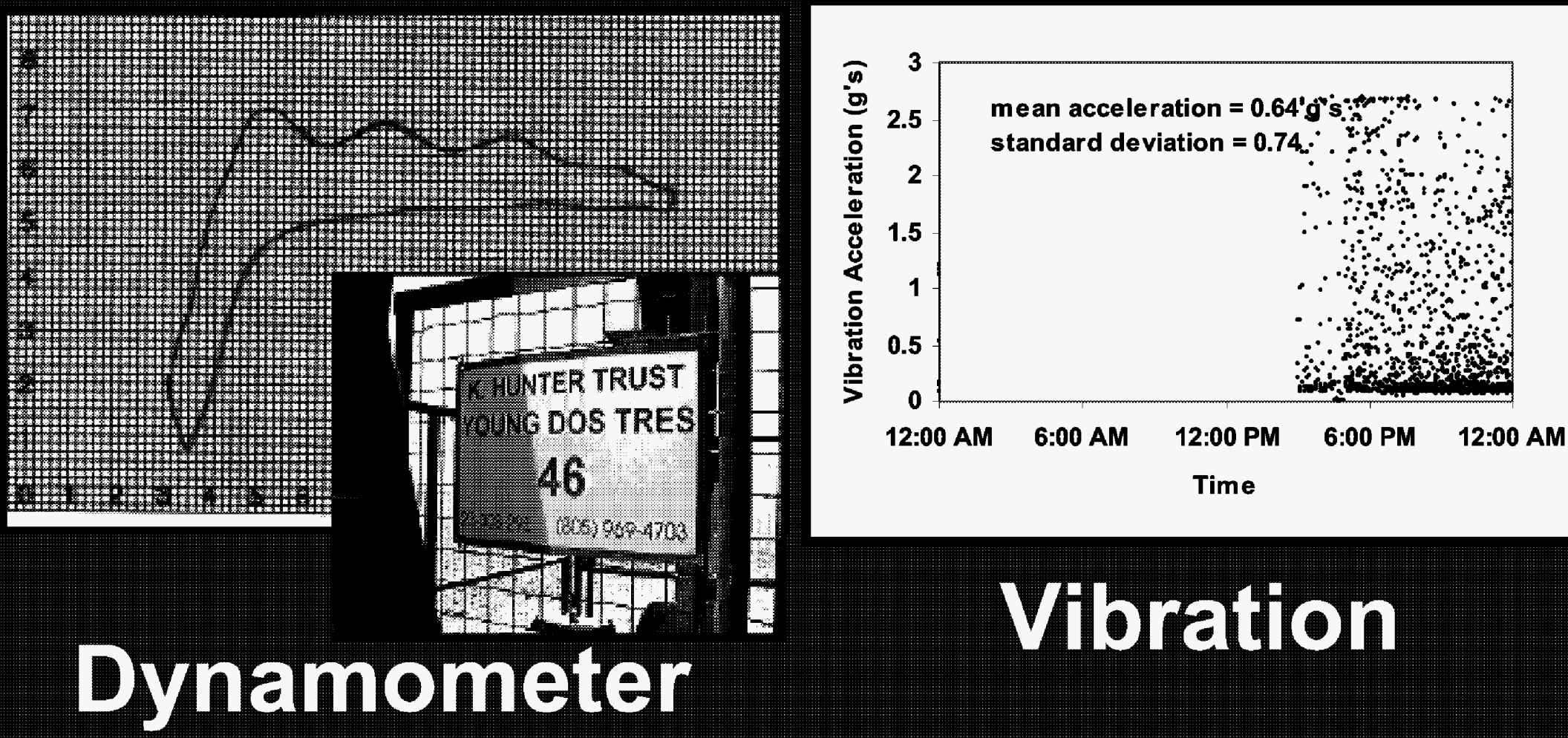

Vibration 


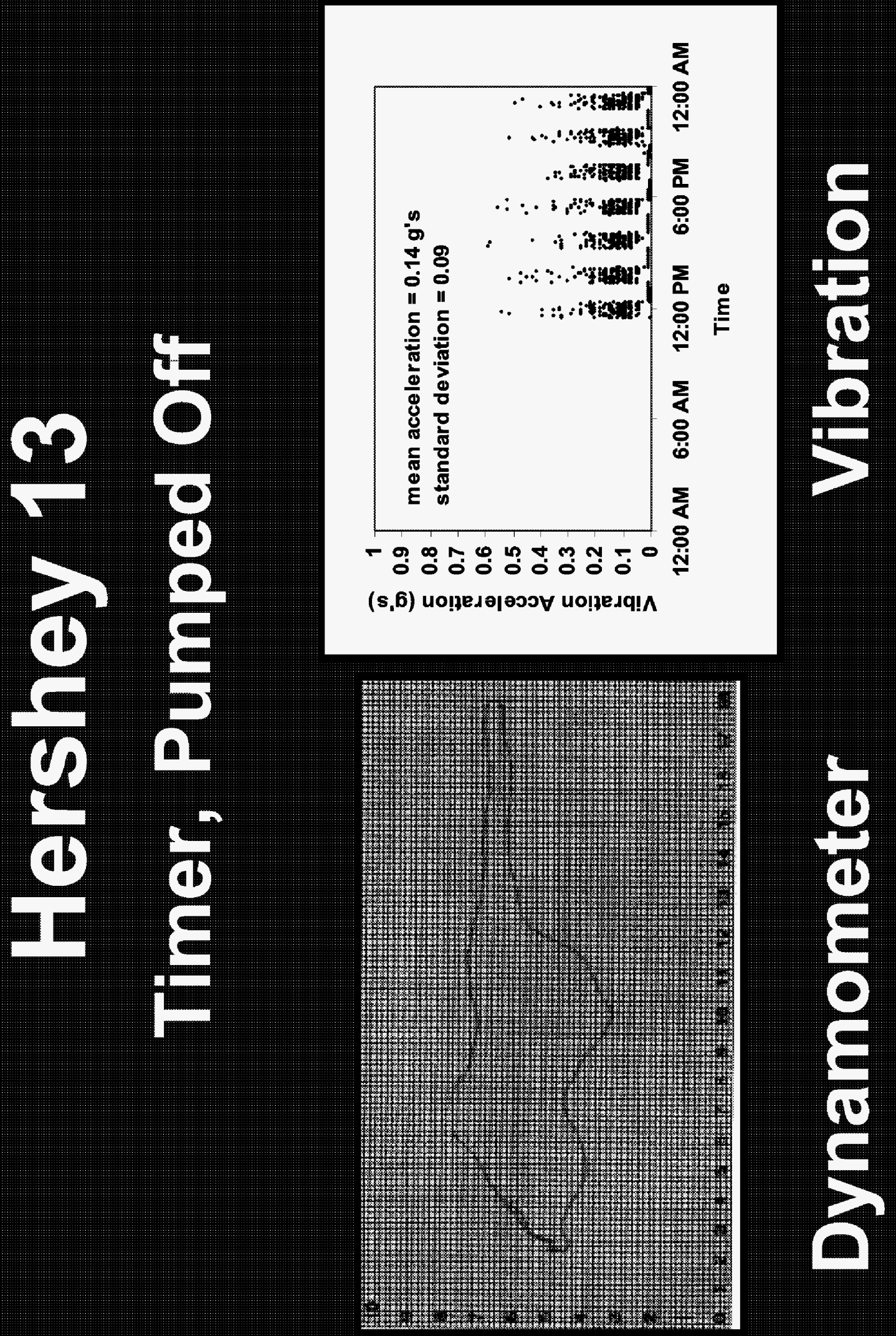




\section{Young Fee 11 Not Pumped Off, Under Capacity}

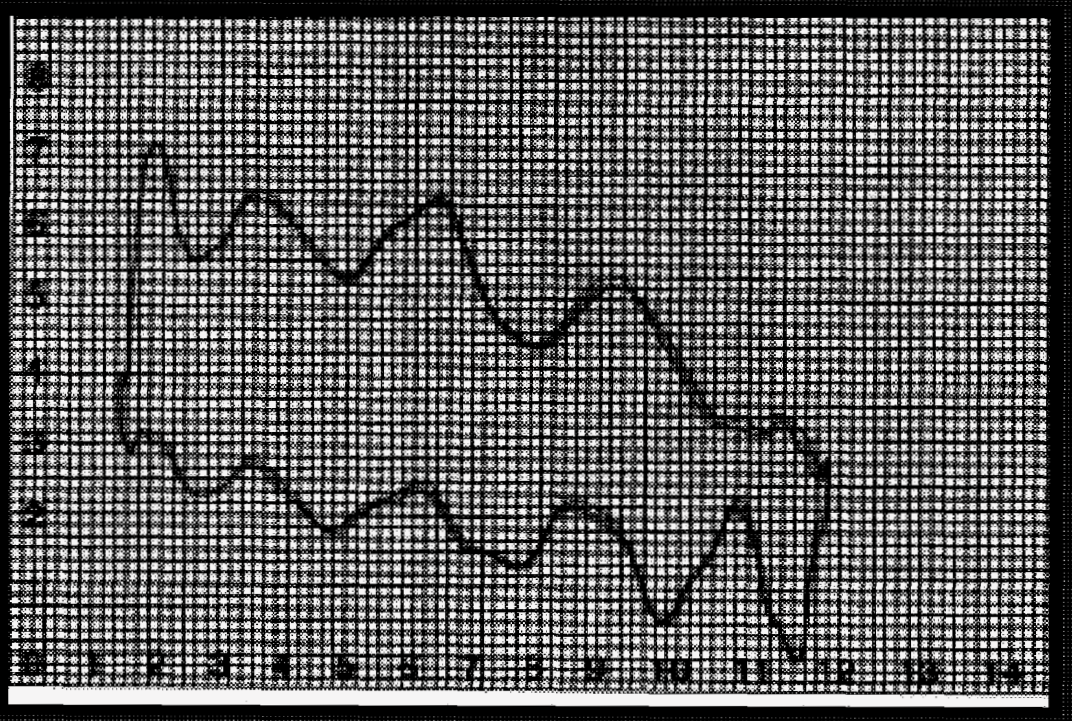

Dynamometer

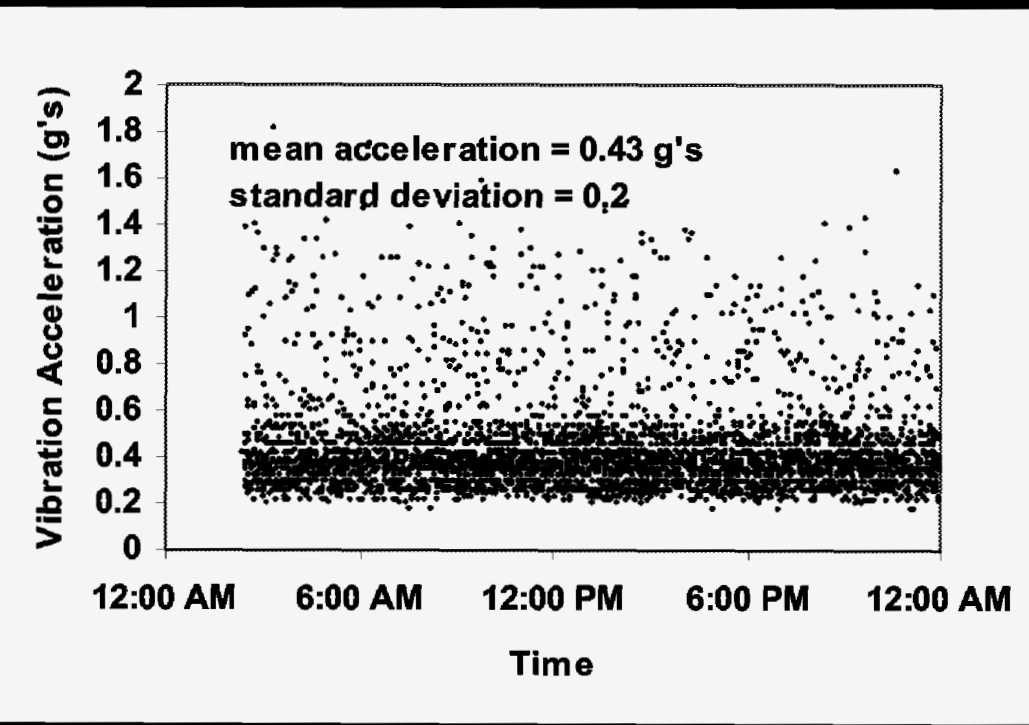

Vibration 

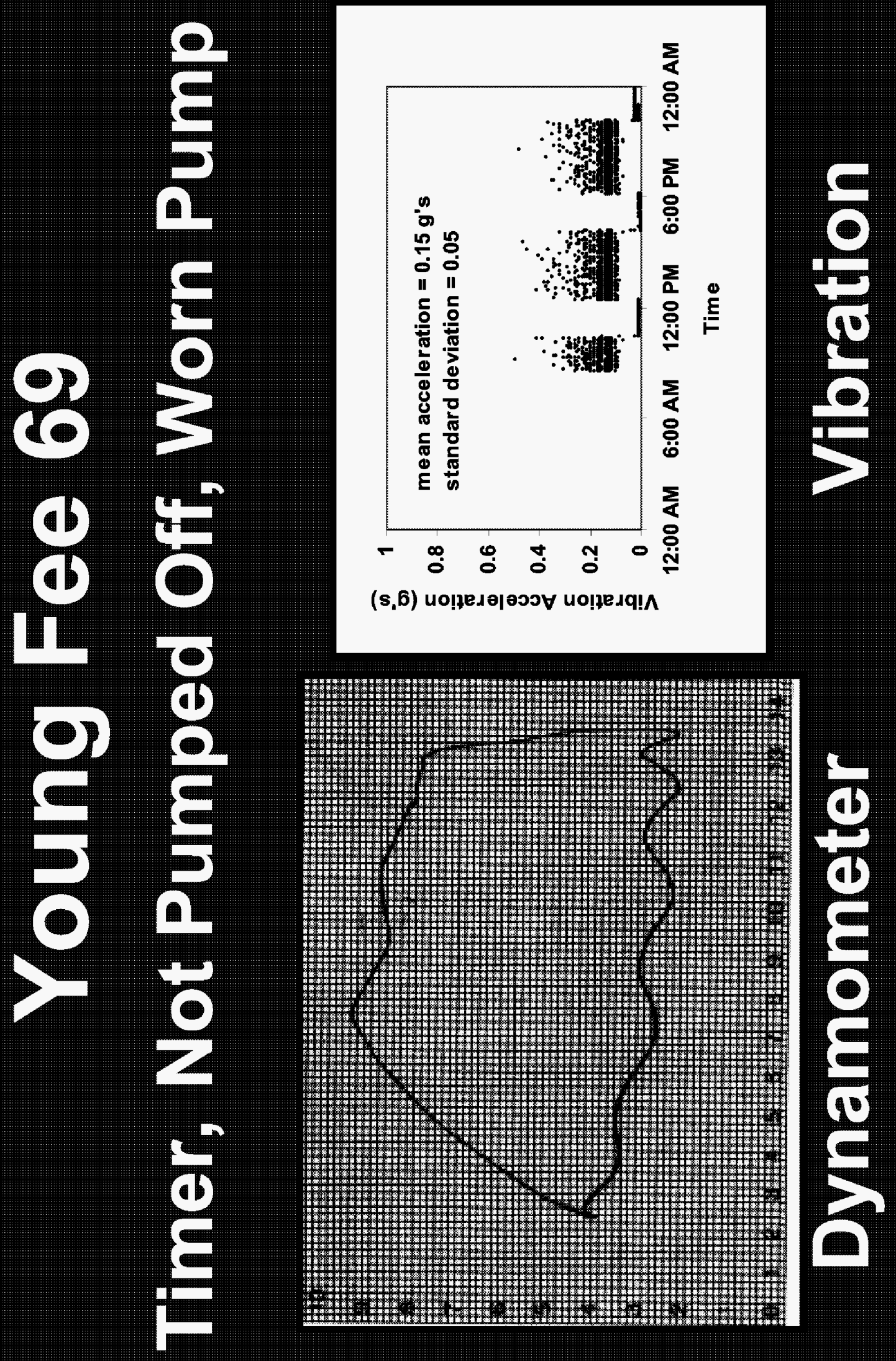


\section{Acceleration Showed \\ Whether Well is Pumped Off}

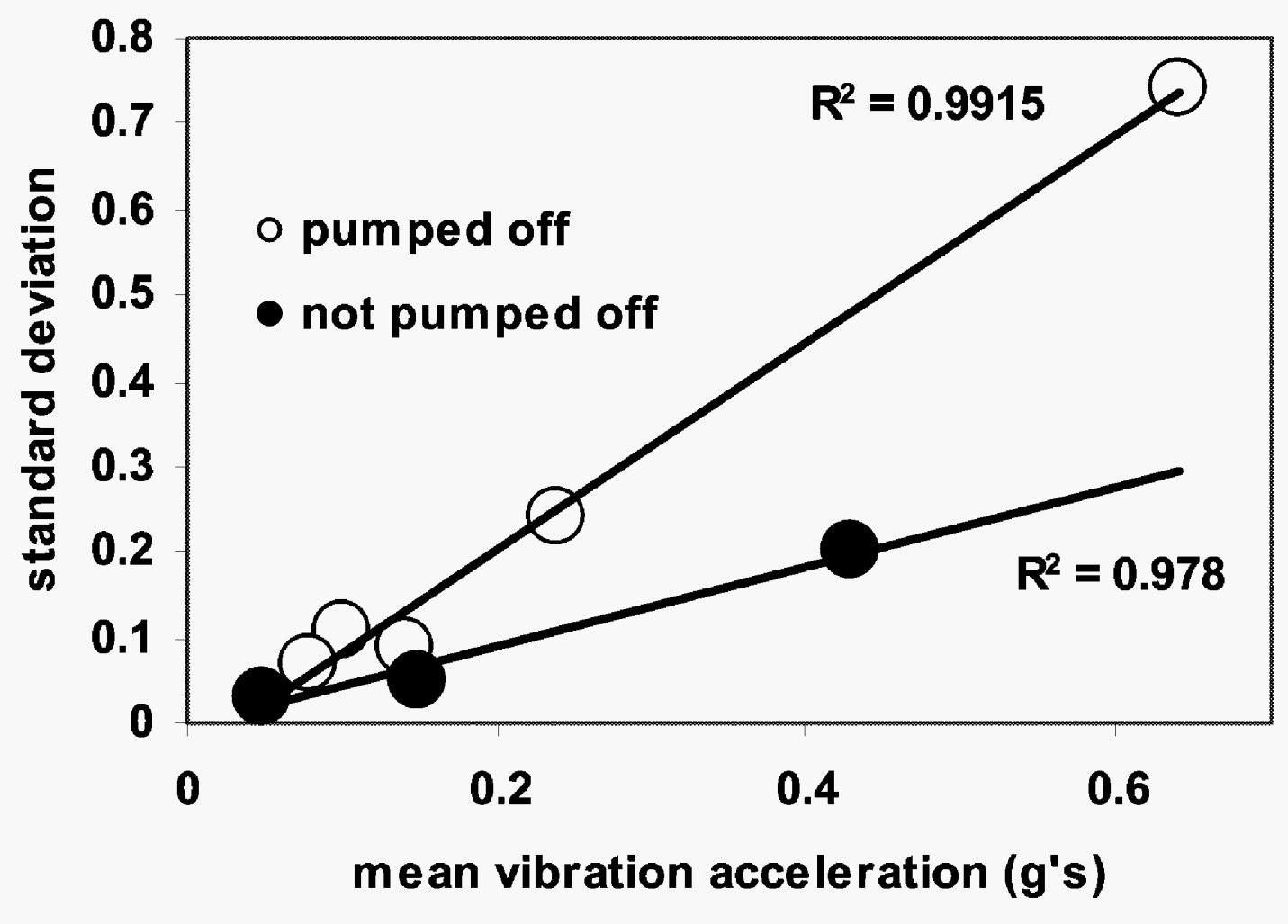




\section{Velocity Did Not Show \\ Whether Well is Pumped Off}

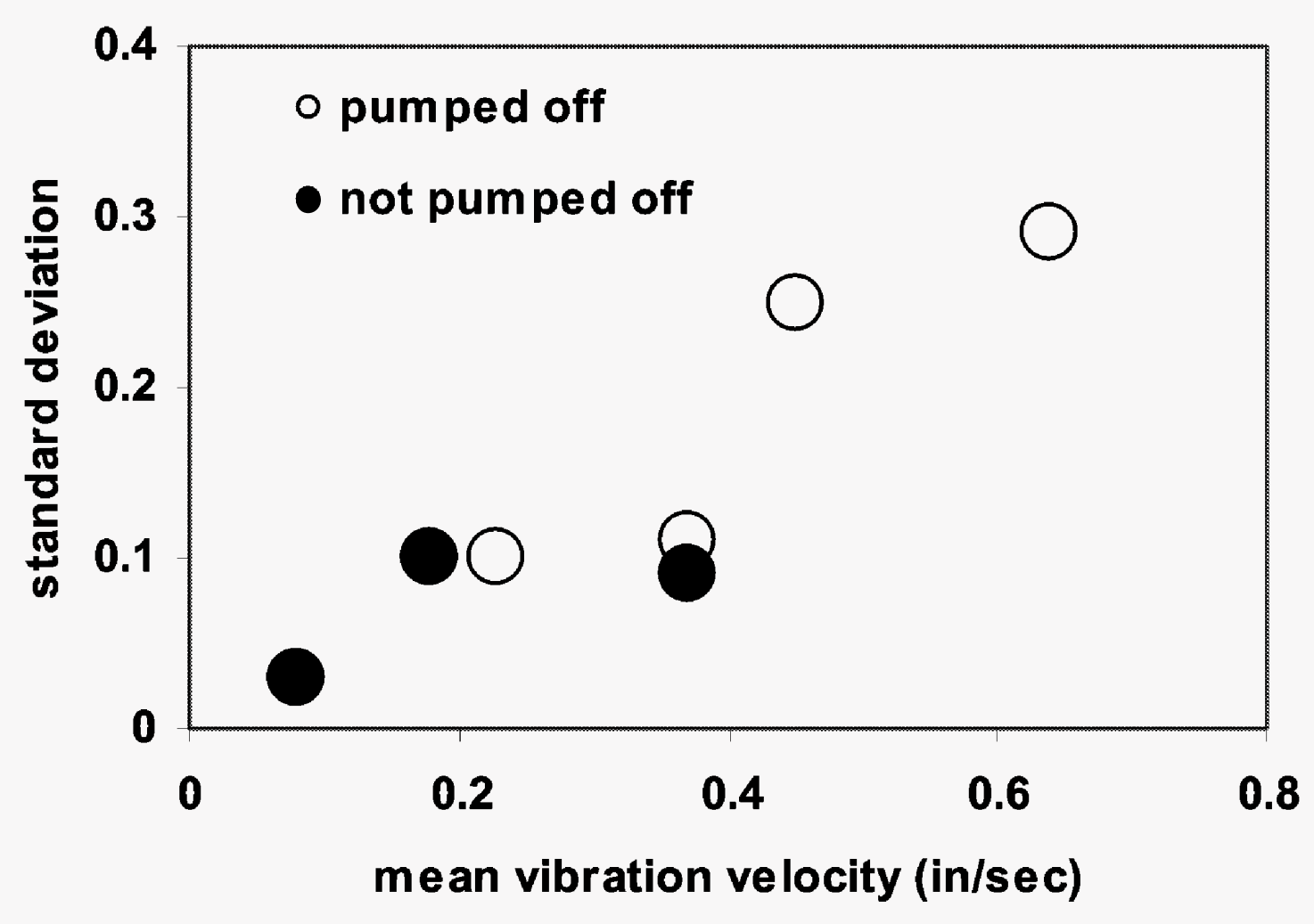




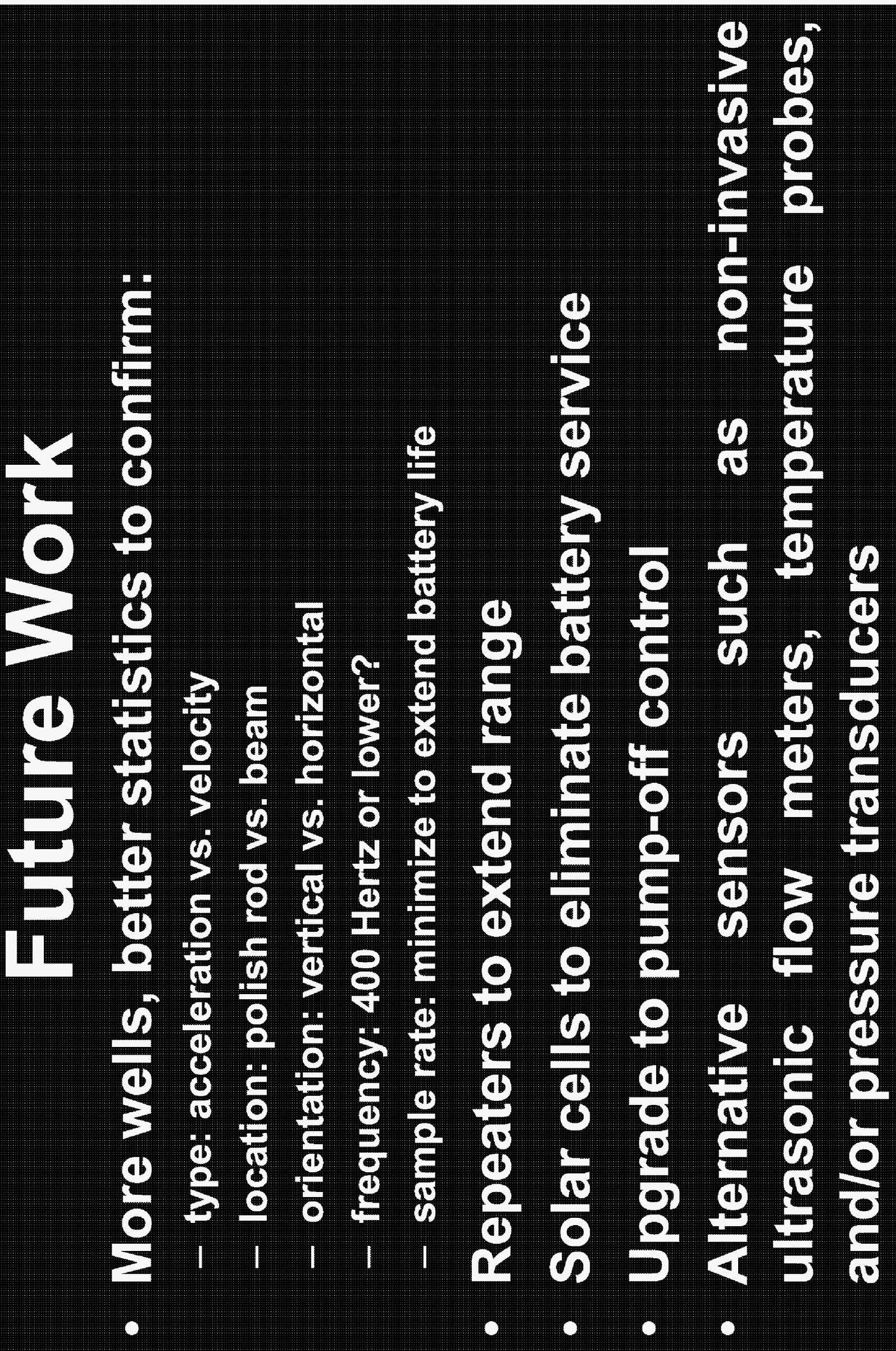




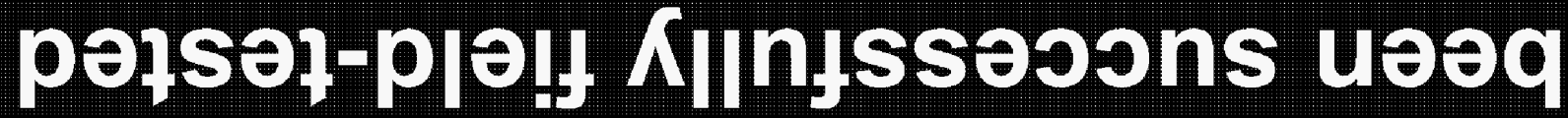

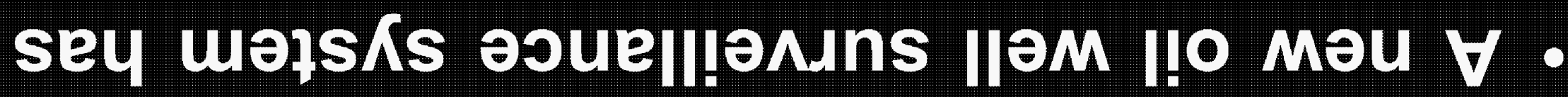

punod

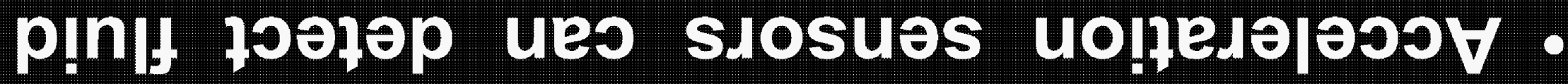

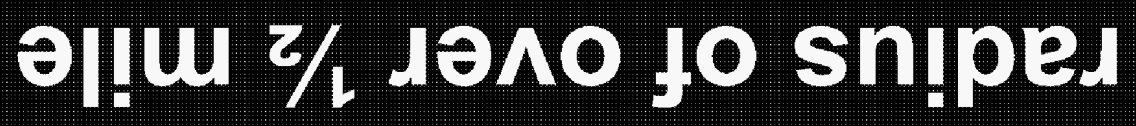

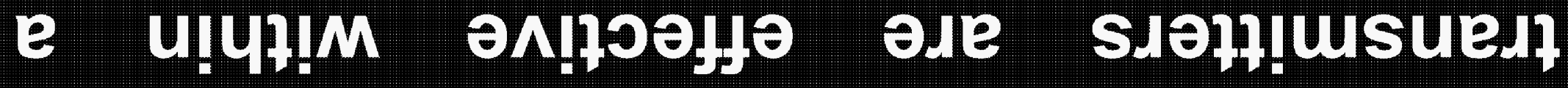
olpes unnpods-peajds 'Jamod MO7. әмцәәуә әле smous әрелl •

\section{suojsnjouog}




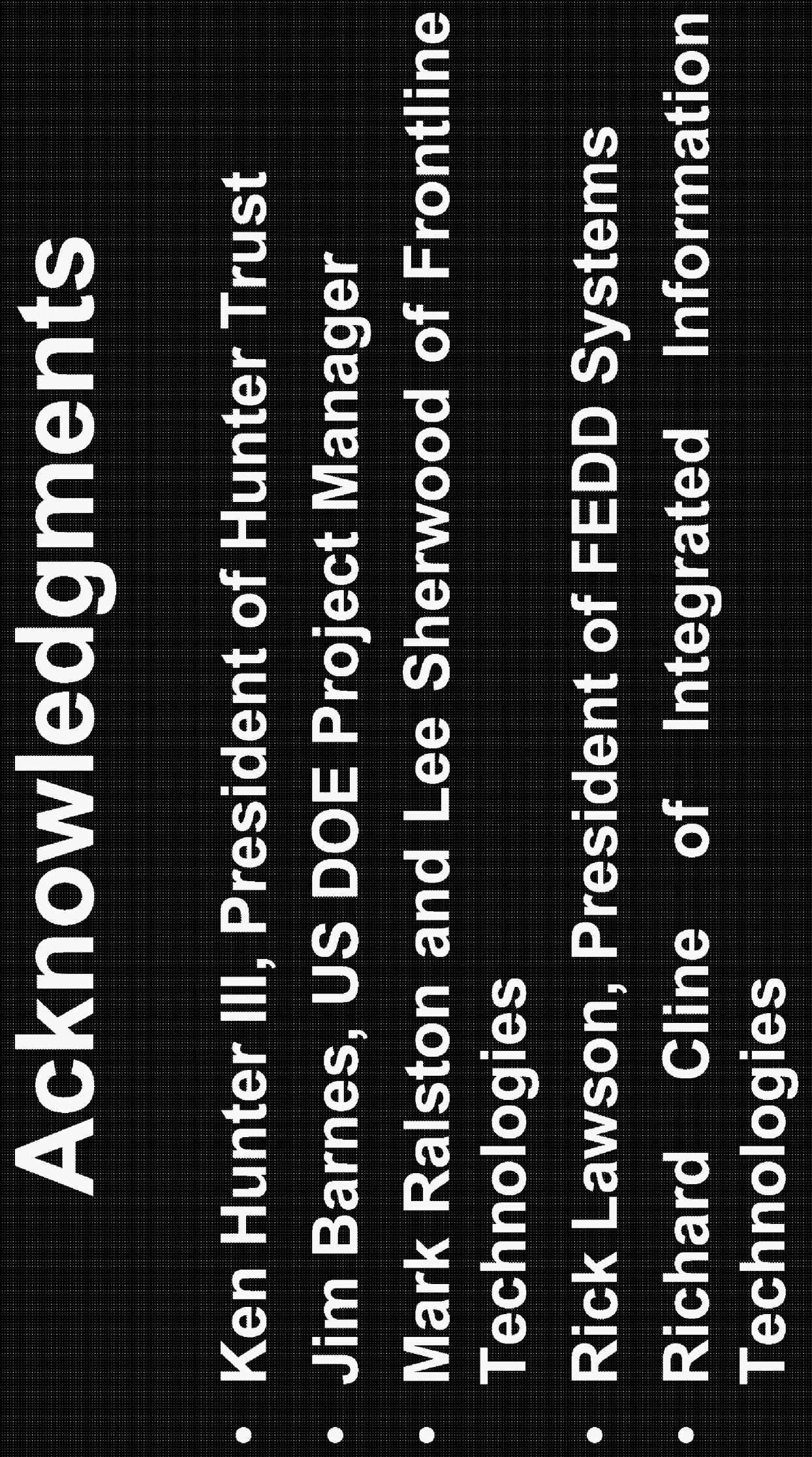




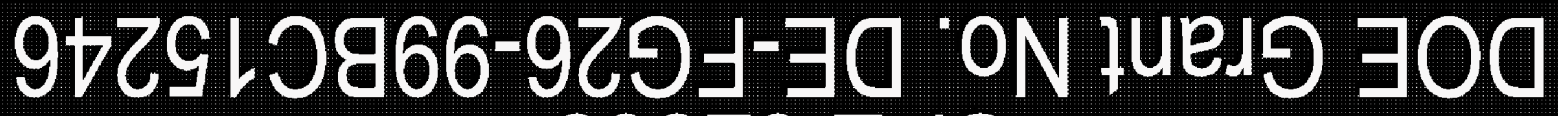 s9829 $\exists d S$}

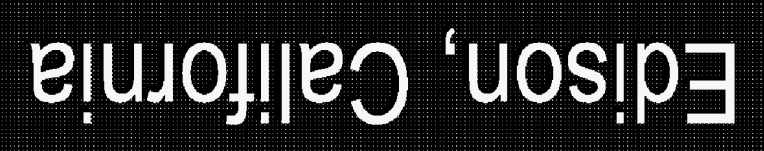

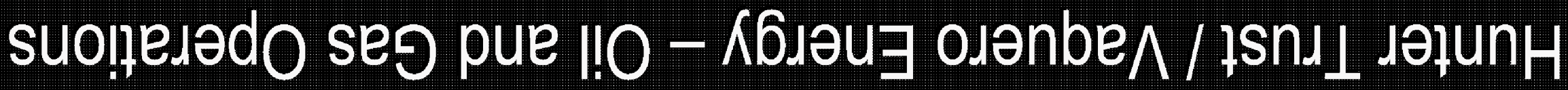

\section{UOS|əN UOC}

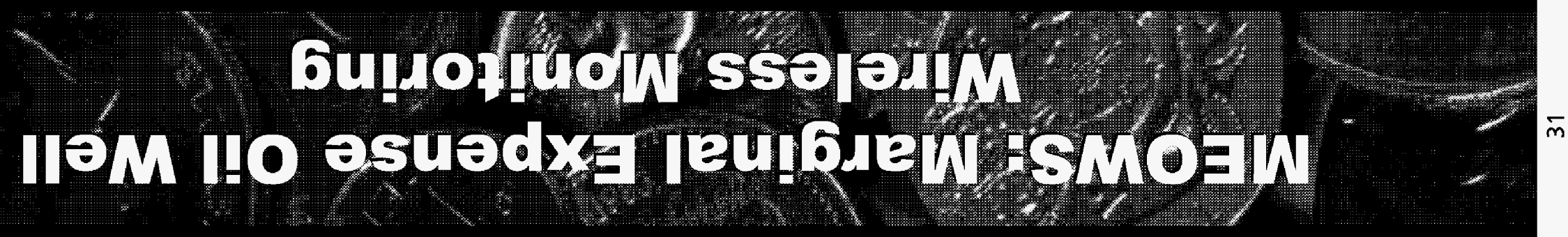

\section{Gugromine}

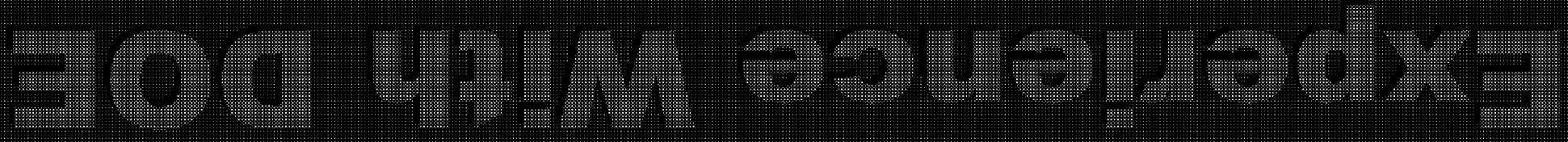

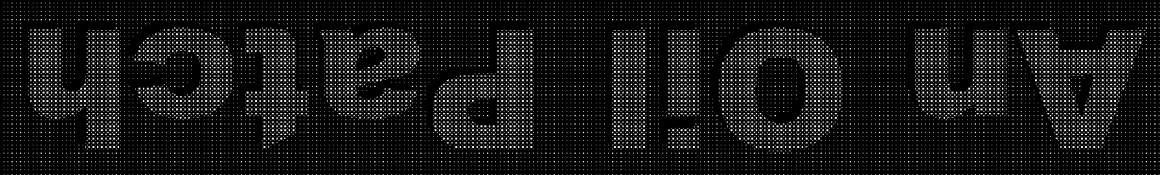




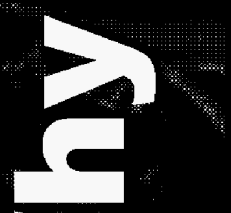

(a)

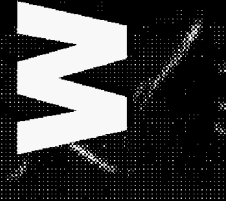

(b)

(9)

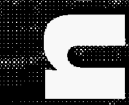

10

)

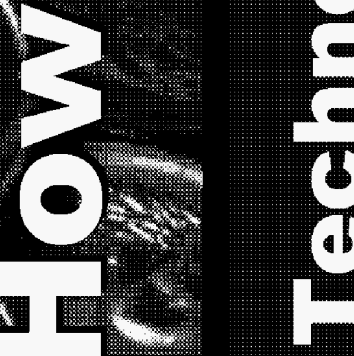

40

(e)

1

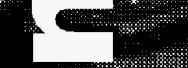



5

(3)

$x=1$

20

Th

14.

i11

( ) $2 \leq \frac{1}{2}$
6

8

0

8

(1)

$E$

E

(1)

C i 2

$+$

(1) $\Omega$

한

50 m

is

6

0

1
EN

6

$\underset{8}{8}$

$F$

H

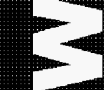

불

(1)

ด $\frac{1}{8}=$ 


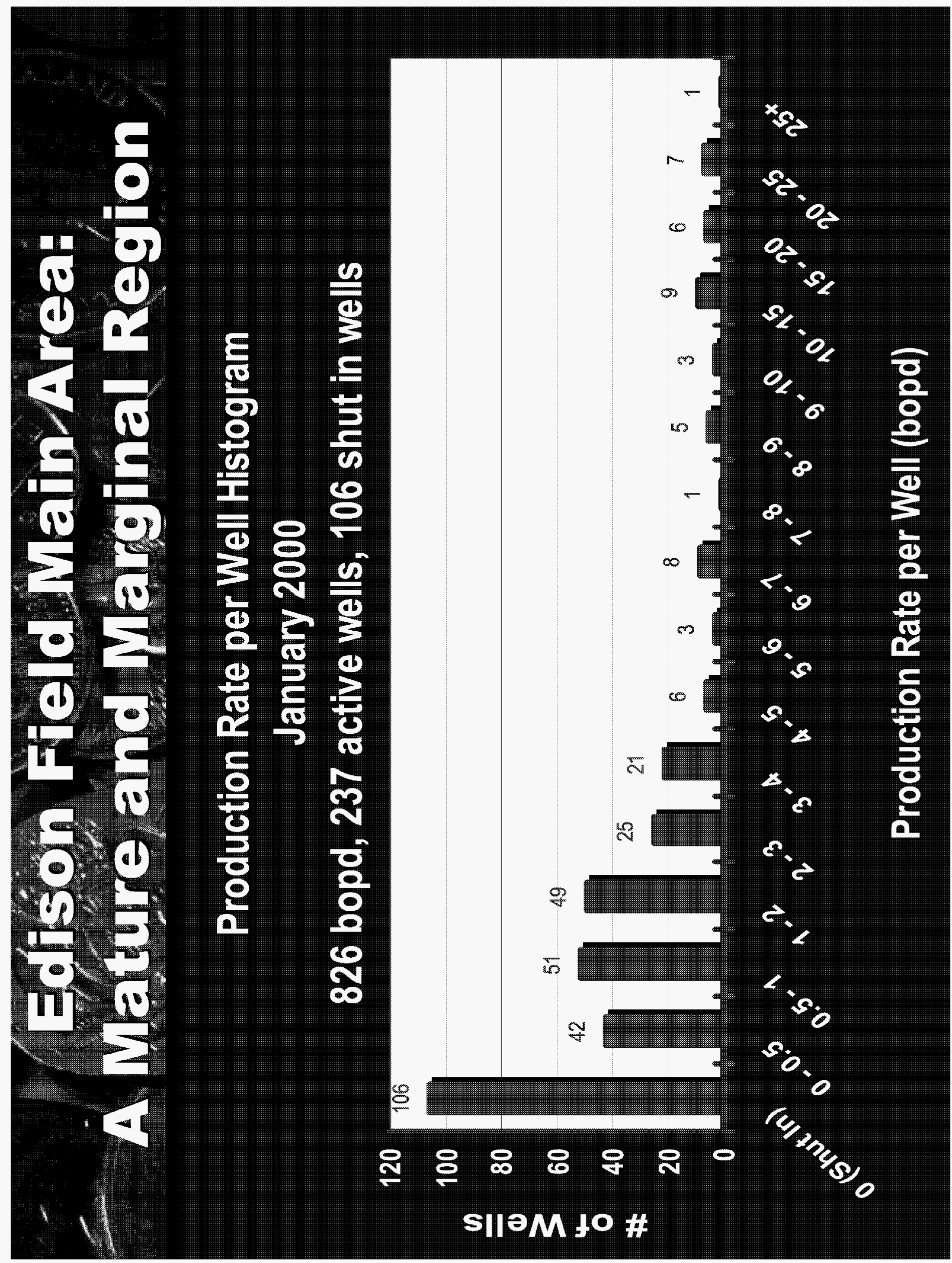




\section{Challenges for Stripper Wells}

- Infrequent production tests

- Allocation meters do not flag problem wells

- Failed wells undetected until polish rod smokes

- Low production wells undetected until production test

- Time clocks complicate surveillance

- Low oil rates do not justify high cost systems 


\section{ARejected Migh-Cost Alternatives}

- Conventional wireless, pump-off control systems

- Individual flow lines and automatic well testing facilities

- Frequent dynamometer surveys

- Frequent fluid level surveys

- Frequent well tests with portable testers 


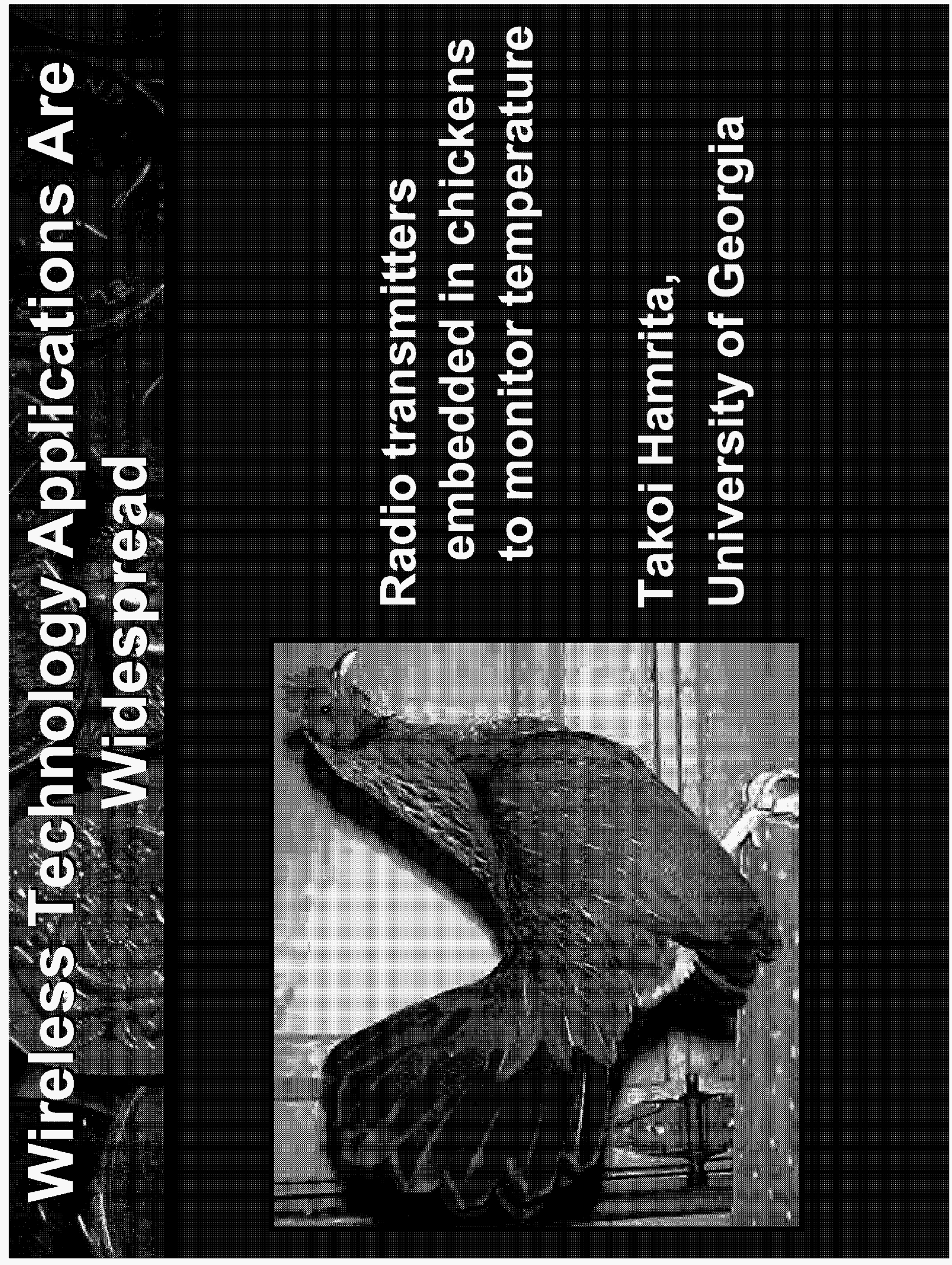




\section{Whration Sensor I
- Wireless Transmitter Unit}

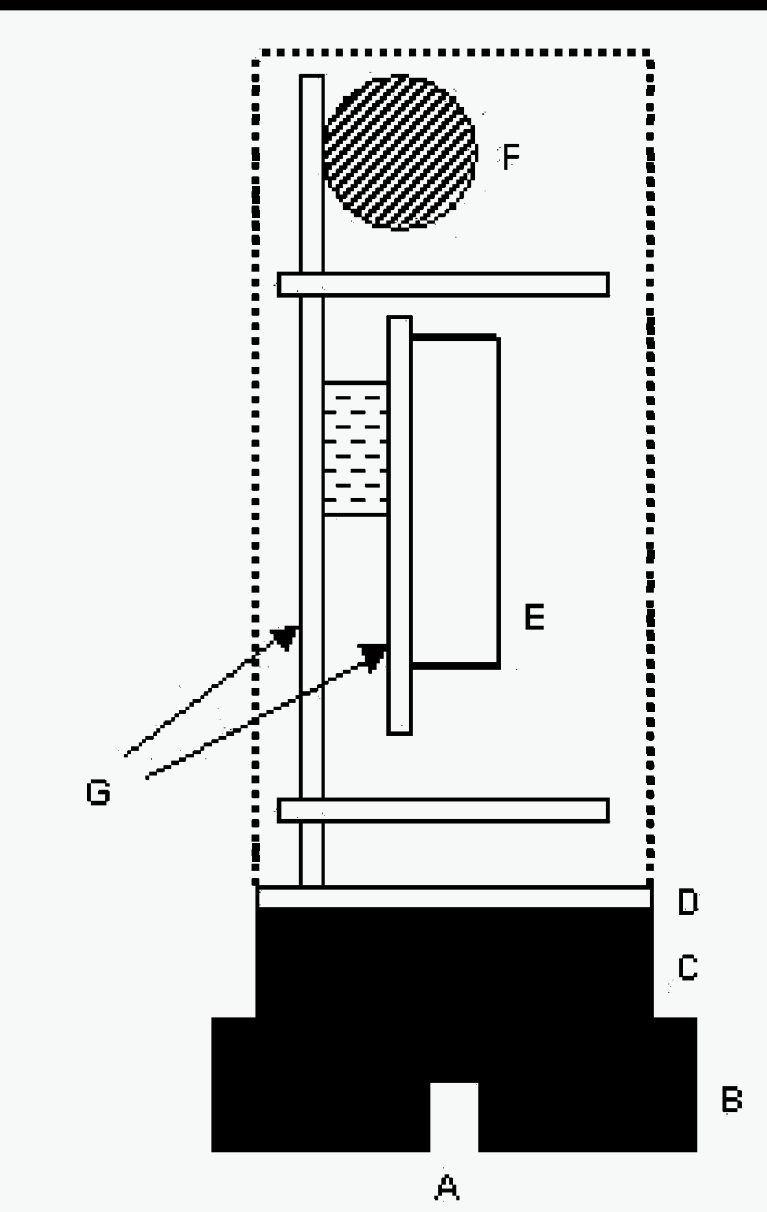
A) 1/4" $\times 28$-thread mounting bore

B) stainless steel base

C) vibration sensing element and O-ring

D) sensor board

E) radio antenna

F) battery

G) circuit boards. 


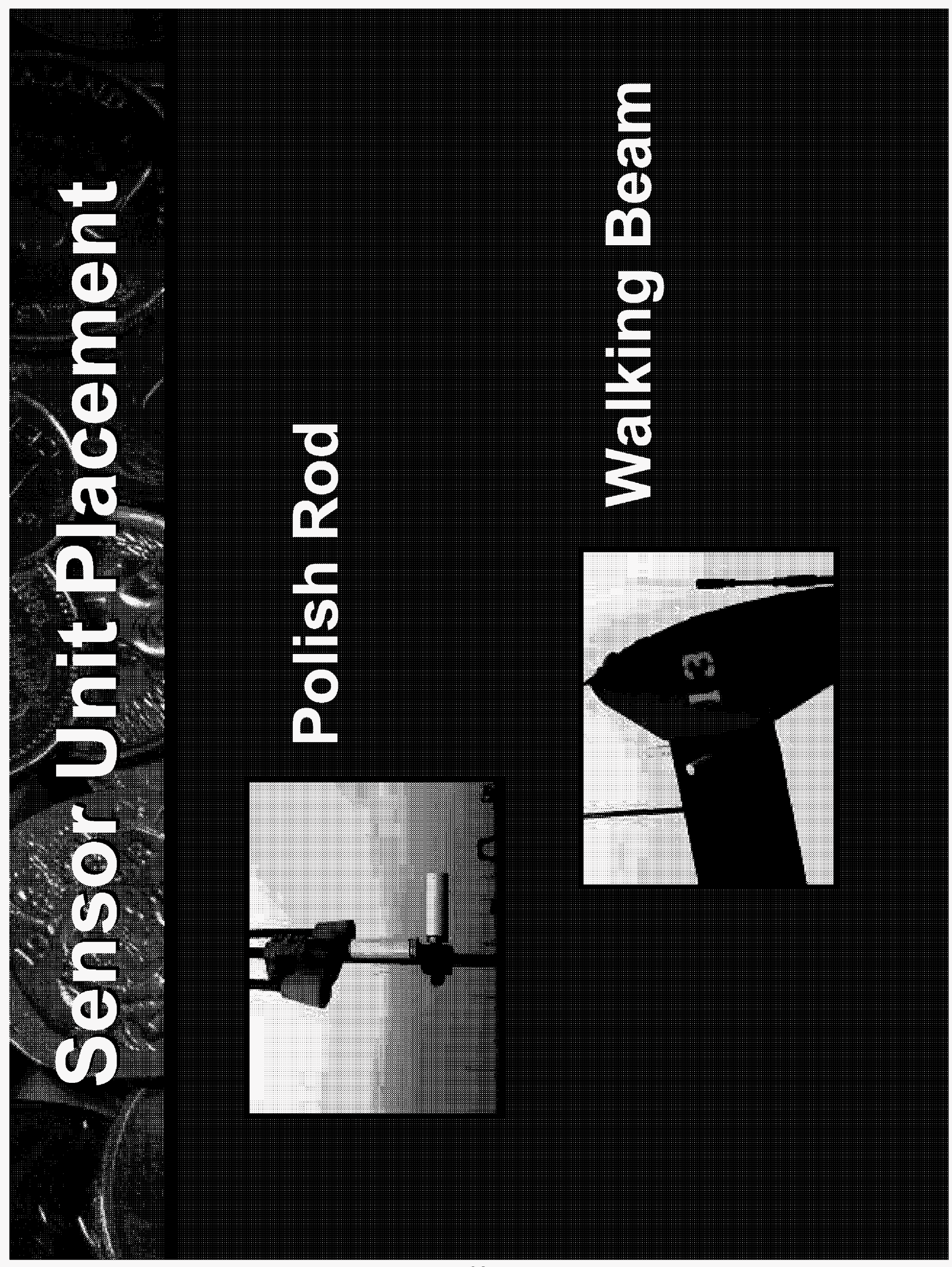




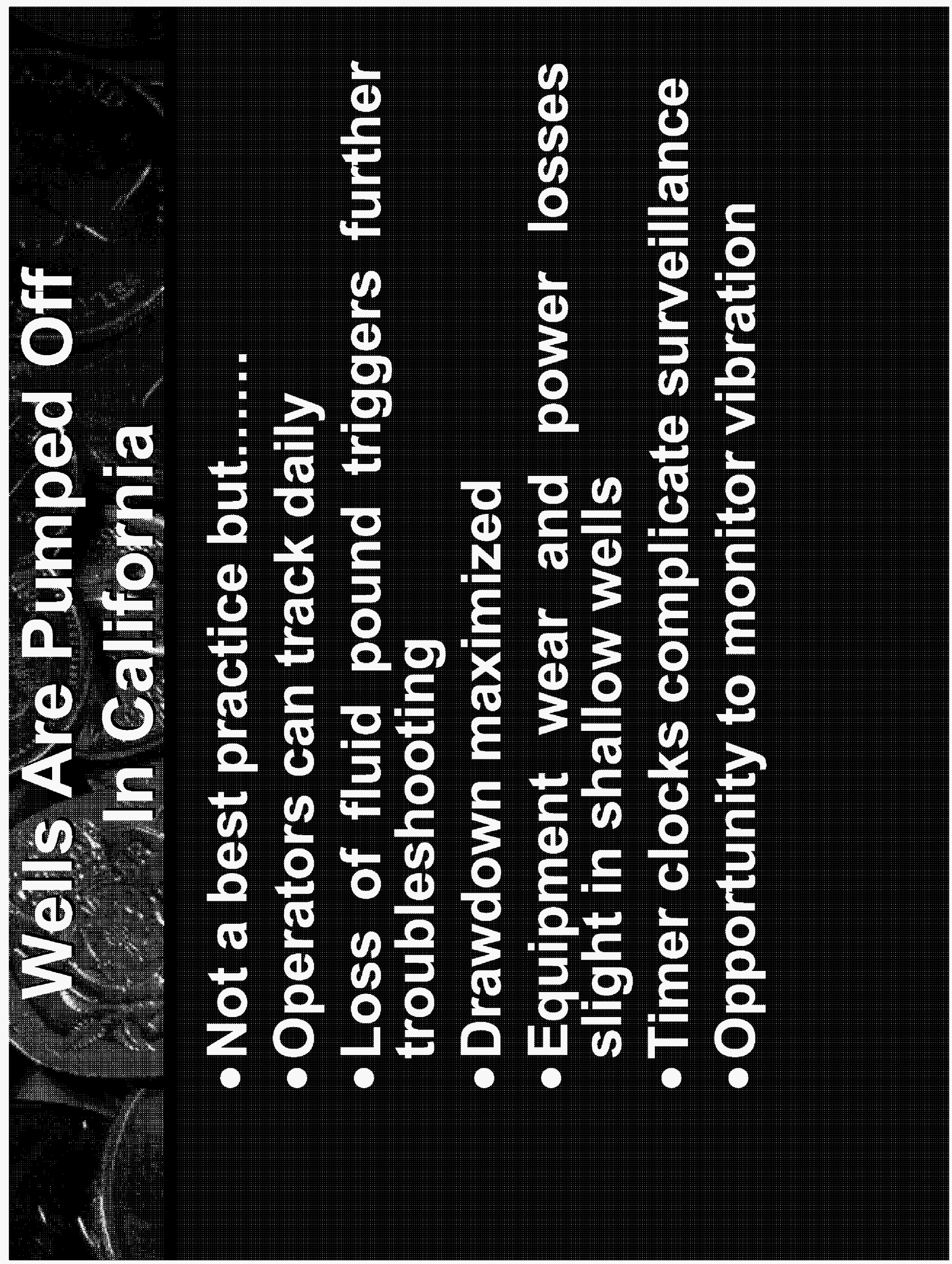




\section{- Test Results Summary}

\begin{tabular}{|c|c|c|c|c|c|c|c|c|c|} 
sensor type & location & orientation & median & mean & $\begin{array}{c}\text { standard } \\
\text { deviation }\end{array}$ & $\begin{array}{c}\text { standard } \\
\text { deviationl } \\
\text { mean }\end{array}$ & $\begin{array}{c}\text { pumped } \\
\text { off? }\end{array}$ & $\begin{array}{c}\text { total } \\
\text { samples }\end{array}$ & well \\
\hline acceleration & polish rod & vertical & 0.24 & 0.64 & 0.74 & 1.16 & yes & 4359 & YF 46 \\
\hline acceleration & beam & horizontal & 0.07 & 0.1 & 0.11 & 1.10 & yes & 4313 & $\mathrm{H} 13$ \\
\hline acceleration & beam & vertical & 0.15 & 0.24 & 0.24 & 1.00 & yes & 3487 & $\mathrm{H} 13$ \\
\hline acceleration & polish rod & horizontal & 0.07 & 0.08 & 0.07 & 0.88 & yes & 4132 & $\mathrm{H} 13$ \\
\hline acceleration & polish rod & vertical & 0.12 & 0.14 & 0.09 & 0.64 & yes & 4157 & $\mathrm{H} 13$ \\
\hline acceleration & beam & vertical & 0.04 & 0.05 & 0.03 & 0.60 & no & 3734 & YF 69 \\
\hline acceleration & polish rod & vertical & 0.38 & 0.43 & 0.2 & 0.47 & no & 7262 & YF 11 \\
\hline acceleration & beam & horizontal & 0.14 & 0.15 & 0.05 & 0.33 & no & 4299 & YF 69 \\
\hline velocity & beam & vertical & 0.16 & 0.18 & 0.1 & 0.56 & no & 3087 & YF 69 \\
\hline velocity & beam & vertical & 0.42 & 0.45 & 0.25 & 0.56 & yes & 1075 & $\mathrm{H} 13$ \\
\hline velocity & polish rod & vertical & 0.63 & 0.64 & 0.29 & 0.45 & yes & 2054 & $\mathrm{H} 13$ \\
\hline velocity & beam & horizontal & 0.21 & 0.23 & 0.1 & 0.43 & yes & 4670 & $\mathrm{H} 13$ \\
\hline velocity & beam & horizontal & 0.08 & 0.08 & 0.03 & 0.38 & no & 4413 & YF 69 \\
\hline velocity & polish rod & horizontal & 0.37 & 0.37 & 0.11 & 0.30 & yes & 1351 & $\mathrm{H} 13$ \\
\hline velocity & polish rod & horizontal & 0.37 & 0.37 & 0.09 & 0.24 & no & 4729 & YF 11 \\
\hline
\end{tabular}




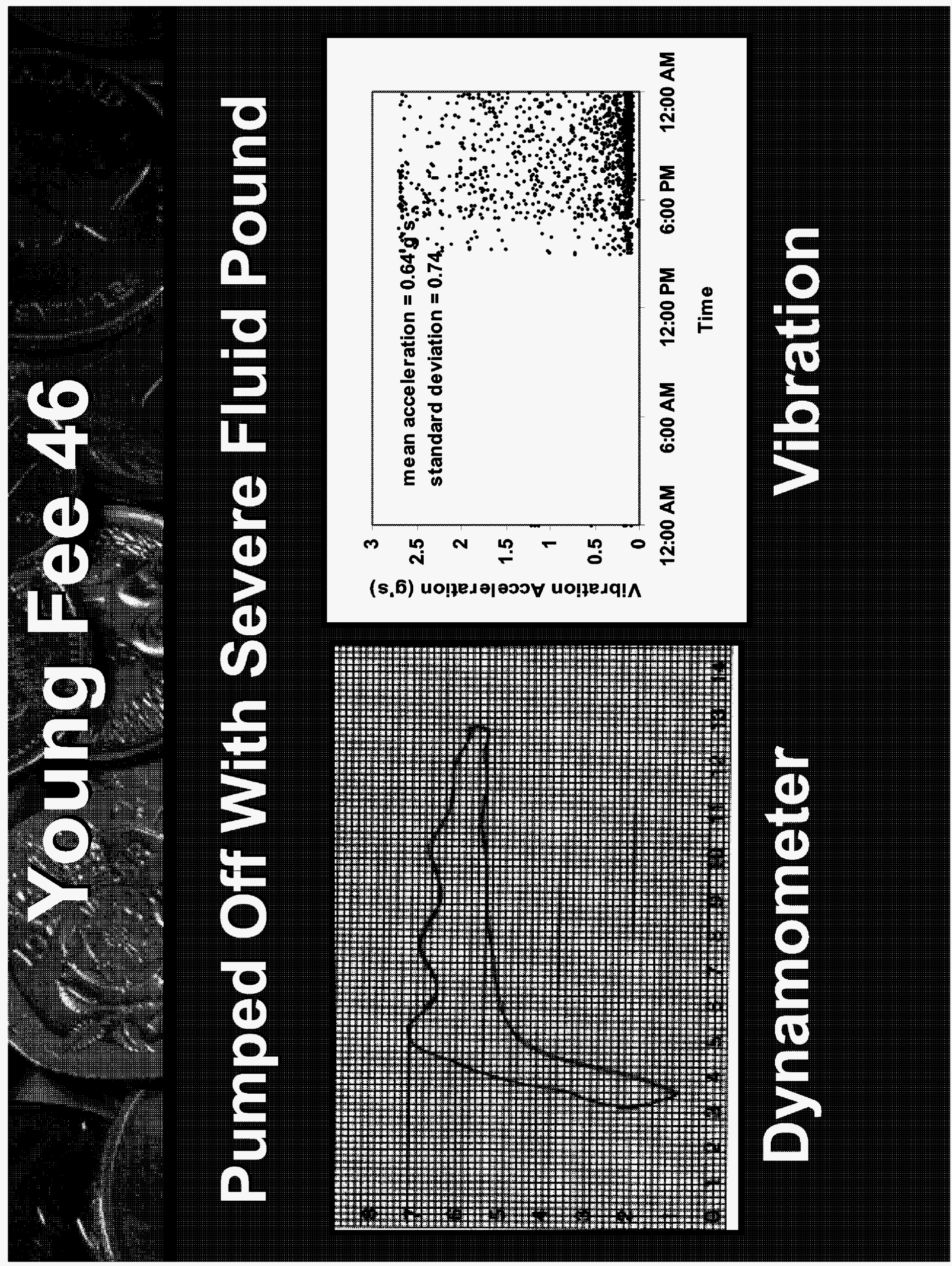




\section{- $\quad$ foung Fee 11 \\ Not Pumped Off, Under Capacity}

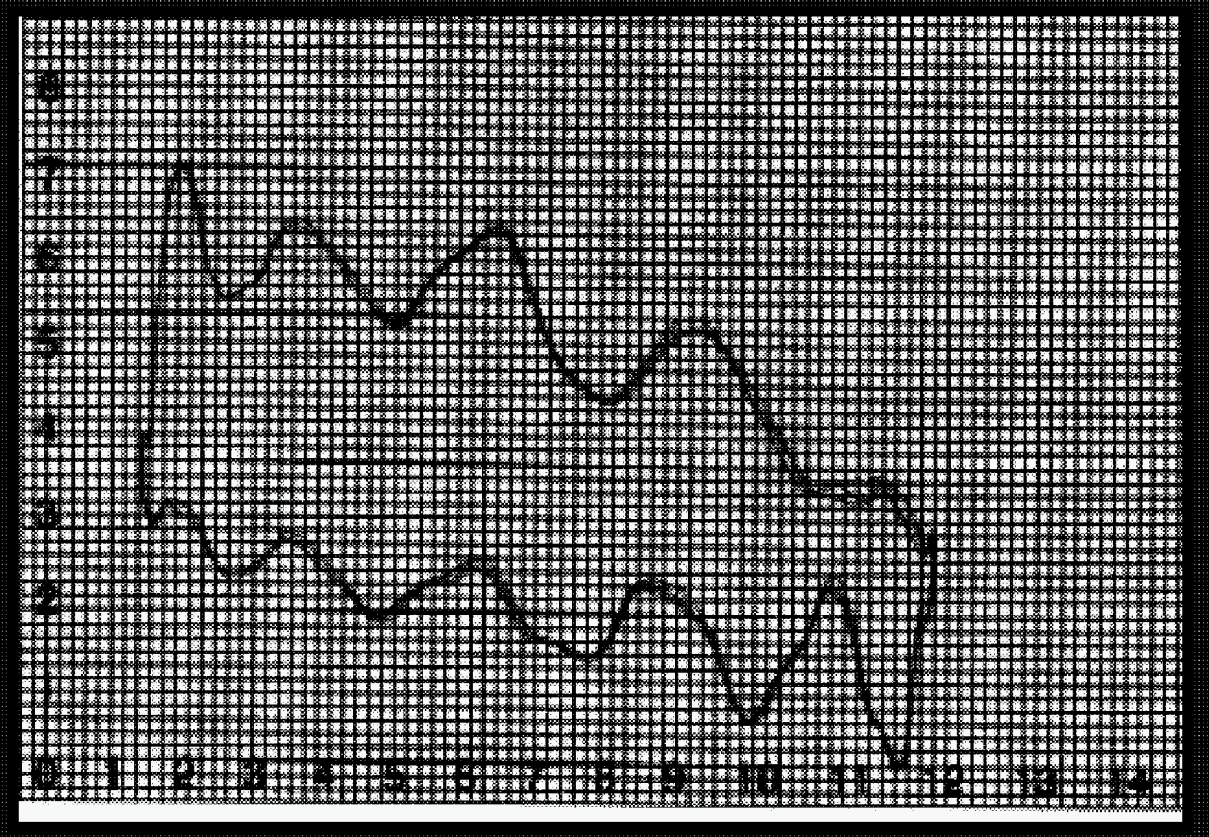

Dynamometer

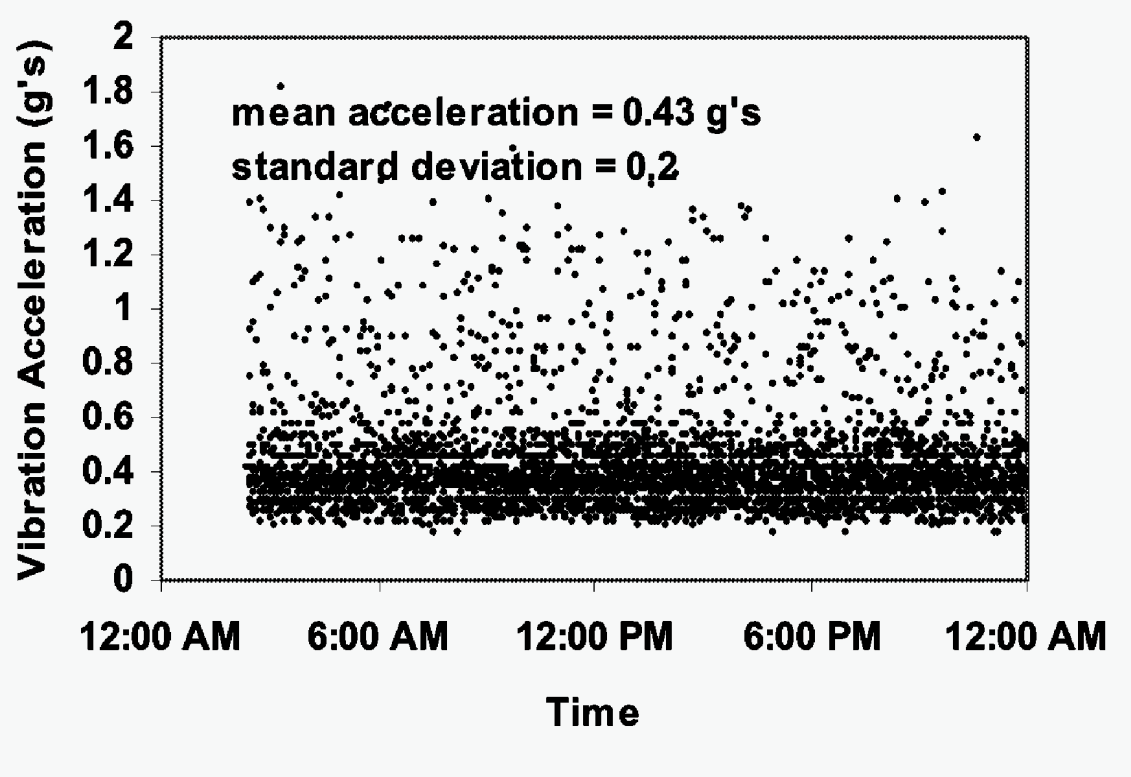

Vibration 


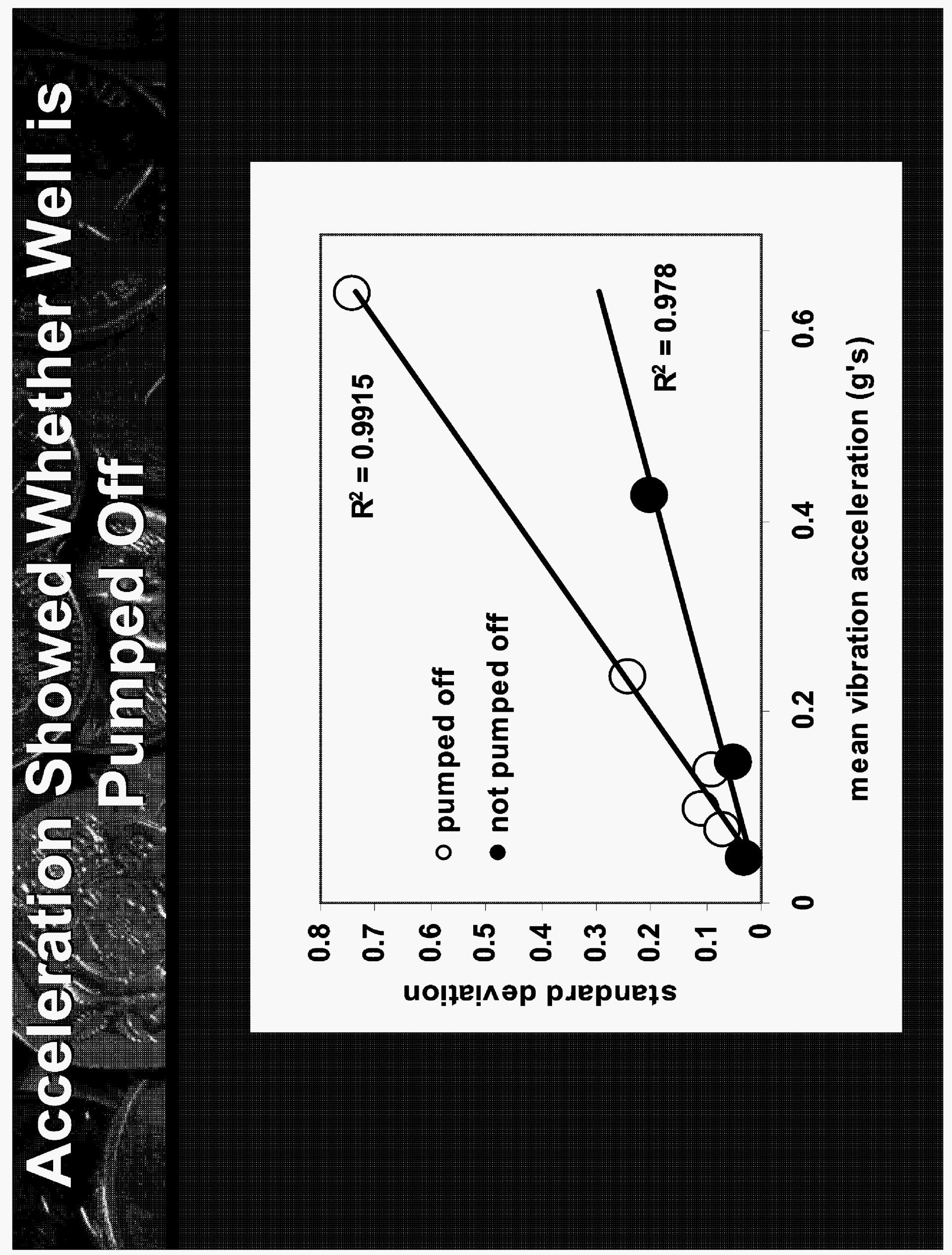




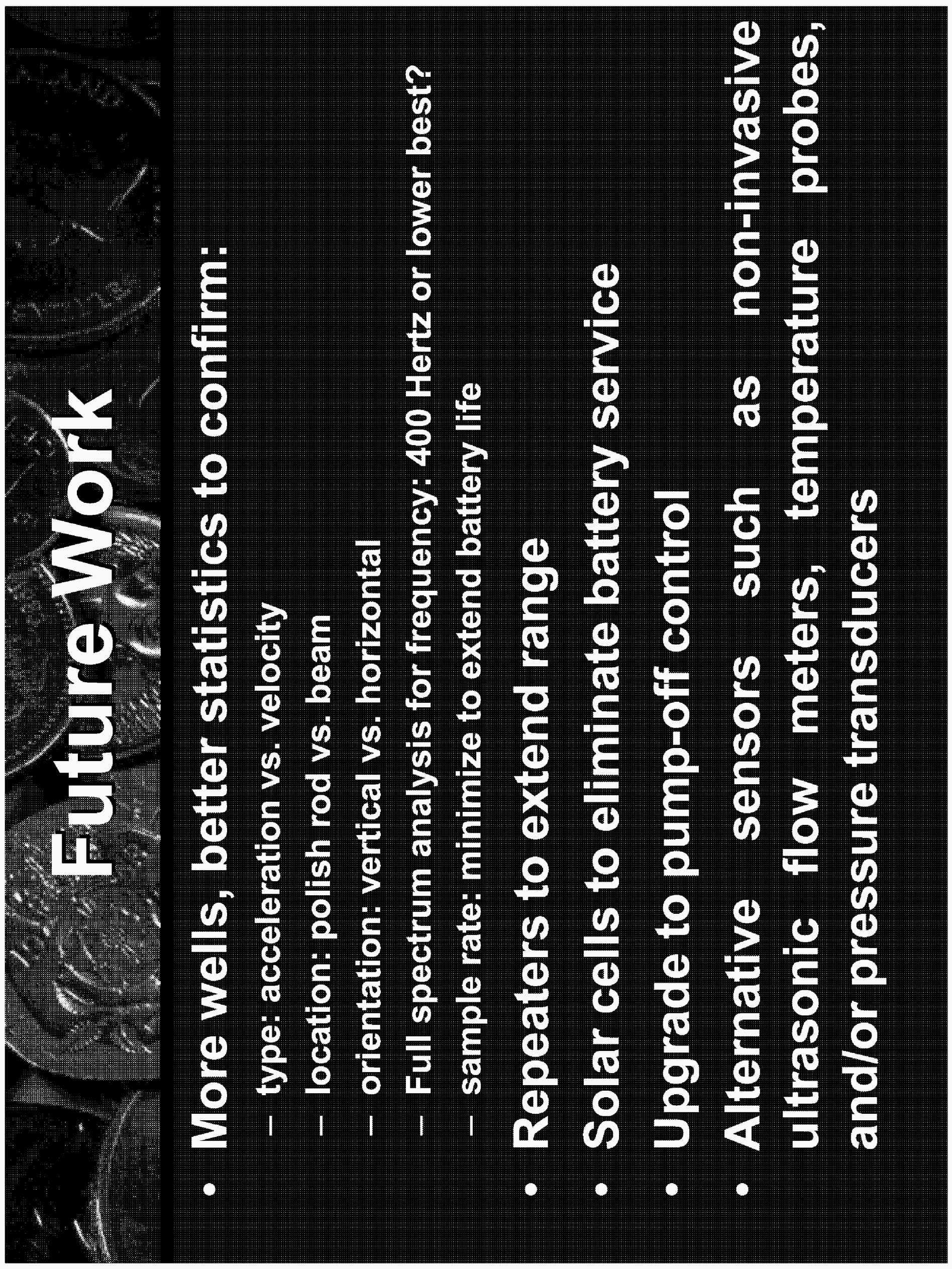




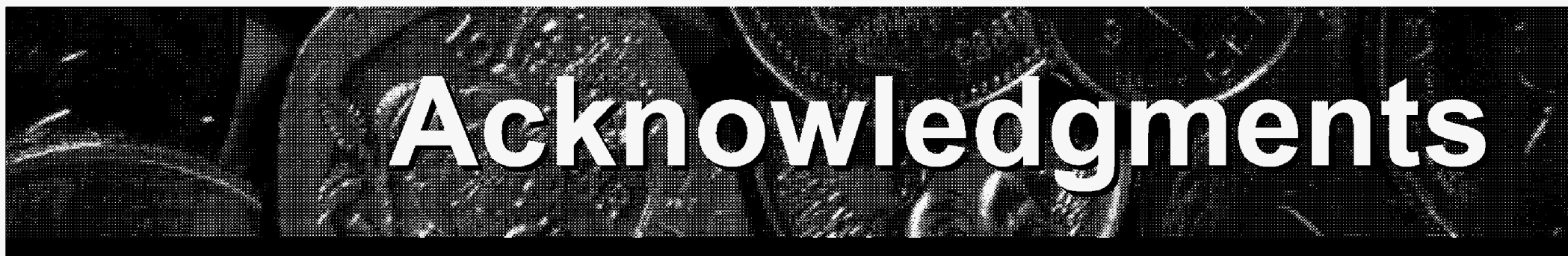

- Ken Hunter III, President of Hunter Trust

- Jim Barnes, US DOE Project Manager

- Mark Ralston and Lee Sherwood of Frontline Technologies

- Rick Lawson, President of FEDD Systems

- Richard Cline of Integrated Information Technologies 

